\title{
Developmental Disabilities Across the World: A Scientometric Review from 1936 to 2020
}

\author{
Alessandro Carollo ${ }^{\mathrm{a}}$, Andrea Bonassi ${ }^{\mathrm{a}, \mathrm{b}}$, Mengyu Lim ${ }^{\mathrm{c}}$, Giulio Gabrieli ${ }^{\mathrm{c}}$, \\ Peipei Setoh ${ }^{c}$, Dagmara Dimitriou ${ }^{\mathrm{d}}$, Vahid Aryadoust ${ }^{\mathrm{f}}$, Gianluca \\ Esposito $^{\mathrm{a}, \mathrm{c}, \mathrm{e}, *}$ \\ ${ }^{a}$ Department of Psychology and Cognitive Science, University of Trento, Rovereto, Italy \\ ${ }^{b}$ Mobile and Social Computing Lab, Bruno Kessler Foundation, Trento, Italy \\ ${ }^{c}$ Psychology Program, School of Social Sciences, Nanyang Technological University, \\ Singapore, Singapore \\ ${ }^{d}$ Sleep Research and Education Laboratory, UCL Institute of Education, London, United \\ Kingdom \\ ${ }^{e}$ Lee Kong Chian School of Medicine, Nanyang Technological University, Singapore, \\ Singapore \\ ${ }^{f}$ National Institute of Education, Nanyang Technological University, Singapore, Singapore
}

\begin{abstract}
Background: Developmental disabilities have been largely studied in the past years. Their etiological mechanisms have been underpinned to the interactions between genetic and environmental factors. These factors show variability across the world. Thus, it is important to understand where the set of knowledge obtained on developmental disabilities originates from and whether it is generalizable to low- and middle-income countries. Aims: This study aims to understand the origins of the available literature on developmental disabilities, keeping a focus on parenting, and identify the main trend of research. Methods and Procedure: A sample of 11,315 publications from 1936 to 2020 were collected from Scopus and a graphical country analysis was conducted. Furthermore, a qualitative approach enabled the clustering
\end{abstract}

\section{*Document Published:}

Carollo, A., Bonassi, A., Lim, M., Gabrieli, G., Setoh, P., Dimitriou, D., Aryadoust, V., \& Esposito, G. (2021). Developmental disabilities across the world: A scientometric review from 1936 to 2020. Research in Developmental Disabilities, 117, 104031. https://doi.org/10.1016/j.ridd.2021.104031

Email address: gianluca.esposito@ntu.edu.sg | gianluca.esposito@unitn.it (Gianluca Esposito) 
of references by keywords into four main areas: "Expression of the disorder", "Physiological factors", "How it is studied" and "Environmental factors". For each area, a Document Co-citation Analysis (DCA) on CiteSpace software was performed. Outcomes and Results: Results highlight the leading role of North America in the study of developmental disabilities. Trends in the literature and the documents' scientific relevance are discussed in details. Conclusions and Implications: Results demand for investigation in different socio-economical settings to generalize our knowledge.

\section{What this paper adds?}

The current paper tries to provide insight into the origins of the literature on developmental disabilities with a focus on parenting, together with an analysis of the trends of research in the field. The paper consisted of a multidisciplinary and multi-method review. In fact, the review tried to integrate the analysis of the relation between developmental disabilities with a closer look at the scientific contributions to the field across the world. Specifically, the paper integrates a total of 11,315 papers published on almost a century of research (from 1936 to 2020). An initial qualitative analysis on keywords was combined to a subsequent quantitative approach in order to maximize the comprehension of the impact of almost a century of scientific contributions. Specifically, documents were studied with temporal and structural metrics on a scientometric approach. This allowed the exploration of patterns within the literature available on Scopus in a quantitative way. This method not only assessed the importance of single documents within the network. As a matter of fact, the Document Co-Citation Analysis used on CiteSpace software provided insight into the relations existing between multiple documents in the field of research. As a result, the leading role of North America in the literature of developmental disabilities and parenting emerged. This was accompanied by the review of the main trends of research within the existing literature.

Keywords: developmental disabilities, parenting, country analysis, CiteSpace, Document Co-citation Analysis, scientometric review

\section{Introduction}

Developmental disabilities are a group of lifelong conditions in which the 3 individual's physical, learning, or behavioural functioning is compromised in 
the early stages of life with various degrees of impairment [1, 2]. This diagnostic group encompasses the so-called neurodevelopmental disorders (e.g., attention-deficit / hyperactivity disorder, learning disorders, intellectual disabilities, autism spectrum disorder) together with other conditions, such as hearing loss, blindness, stuttering and seizures [3, 4]. Today, what is known is that these conditions have a complex etiology in which both genetic and environmental influences interact and determine the damages or alterations in the development of the nervous system, therefore leading to the disability [5, 6, 7, 8, 9, 10].

However, this interplay between genetic and environmental factors has not always been considered as the underlying determinants of developmental disabilities. Until the second half of the past century, some of these conditions were attributed to scarce and inadequate parental care [11. In this regard, it is worth mentioning the "refrigerator mother theory" [12], in which a lack of maternal warmth was considered the main cause of autism in children, leading to a sense of guilt in the blamed mothers. Although it is known today that autism spectrum disorders, as other developmental disabilities, is not due to a lack of maternal care, nevertheless parental practices have a role in modulating the behavioral outcomes of children with these conditions [13, 14, 15]. In other words, research in the last decades have focused on the regulating role played by caregivers and, especially, the mother. For instance, the positive interactions between caregivers and children with Down syndrome facilitate the children's language development and this has become a key aspect for interventions [16]. Conversely, early episodes of child neglect are linked to negative outcomes, such as lower intelligence quotient and higher levels of attention deficit/hyperactivity disorder symptoms [17].

Despite gains made in current literature about the relationship between parenting practices and child developmental disability, much is still unknown about the precise interactions between parent, child, and other family and external social factors. Particularly, although the "refrigerator mother theory" has since been refuted, and attempts at explaining parenting strategies and developmental disabilities have been put forth by our team [18, 19, 20], important distinctions between maternal and paternal caregiving, as well as caregiving from other sources, are still under-explored. For children with developmental disabilities, negative child outcomes are commonly experienced and also contribute to a negative cycle of lower quality parenting and worse prognosis for the entire family unit in the long-term [21]. This pattern of relationships between parent, child and developmental disability can be seen 
in, for example, the correlation between parental stress and child behavioral adjustment among the population of children diagnosed with Autism Spectrum Disorder (ASD; 22]). There is thus an impetus to understand how we may best protect this vulnerable population [23], and uplift the main stakeholders in caring for children with developmental disabilities.

Furthermore, global studies of developmental disability and parenting are warranted, due to the presence of larger cultural, socioeconomical, and environmental factors that constitute the larger spheres of influence over the parenting and caregiving microsystem [24]. These macrosystems exert direct and indirect influences on both parenting strategies and resources available for caregiving, as well as overall child development. Unfortunately, prevailing biases with many studies stems from the fact that they are conducted on largely homogeneous demographics [25], with an under-representation from nations that are typically poorer economically or fall outside of the Western world. These differences may result in alternative patterns of results not yet uncovered in current research. For example, parents from African, Middle and East Asian and societies hold beliefs about developmental disability that are different from Western cultures [26, 27], which are subsequently used to inform choices on caregiving methods and resource allocation for these children.

In general, the study of parental practises in relation to developmental disabilities has been studied over the decades and across different countries of the world. The importance of studying developmental disabilities and parenting can be understood by taking a closer look at the results from an epidemiological research conducted by Zablotsky et al. [28, in which the authors detected an increased prevalence of developmental disabilities between 2009 and 2017 among US children aged 3 to 17 years. Together with this high prevalence [29], the tendency to live longer than before for people affected by these conditions is also becoming evident [30, 31, 32. Both these trends require serious attention for several reasons. For example, the increased prevalence of developmental disabilities is likely to lead to a larger number of service demands 33, 34 which needs to be adequately addressed in both quantitative and qualitative terms. Also, the increased life expectancy for people living with a developmental disability poses new challenges for the educational systems. As a matter of fact, although having a disorder that becomes clear in the early phases of life, this group of patients needs to acquire a set of skills to allow them to acquire autonomy throughout their whole life [35, 36]. This is especially true to guarantee a good degree of autonomy in 
the long-term, when caregivers' help may not be available anymore [37, 38. For all these reasons, in the past years, educational systems directed their intents on trying to maximize these children's learning process. To do so, some authors, for instance, have tried to understand if the inclusion of a child with a developmental disability in a class of typically developed children has beneficial outcomes or not [39, 40]. At the same time, other authors have studied the effects of the implementation of specific teaching programs and techniques 41, 42.

Within this framework, in order to contribute to the scientific knowledge on developmental disabilities and parenting, this research aims to provide insights with regards to two key aspects. Firstly, the research tries to estimate the quantity of records published on the relationship between developmental disabilities and parenting by conducting a country analysis. Secondly, this review tries to uncover the research domains that, in a dynamic way, gave rise to the existing literature on developmental disabilities. With this purpose, a scientometric approach based on the analysis of co-citations between publications was adopted to identify the relevant documents and their contribution to the trends that gave shape to the literature of the field in a data-driven approach, as in other publications [43, 44]. Specifically, multiple Document Co-citation Analysis (DCA) were performed in regards to four macro areas, namely Expression of the disorder, Physiological Factors, How it is studied and Environmental factors, identified through a qualitative approach.

\section{Methods}

\subsection{Dataset}

For this research, a sample of 11,315 publications dating from 01 January 1936 to 23 March 2020 was collected from Scopus platform. It is relevant to note that the time range of publications depended uniquely on Scopus' availability and no a-priori temporal exclusion criteria was applied. Specifically, the material was collected by using altogether the string of keywords "TITLE-ABS-KEY ( parent* AND ( development* AND disorder* OR intellectual AND disab* OR genetic* OR neurodev*)) AND ( LIMIT-TO ( LANGUAGE, "English" ))". Research keywords were selected to cover a broad sample of publications on developmental disabilities, taking into account both the genetic and the environmental perspectives. In particular, the term referring to parenting (i.e., "parent*") was included for the broad 
influence that parent-related responsibilities have in the literature on developmental disabilities. Also, when defining the research string, terms of specific disorders (e.g., autism, ADHD) or specific parental aspects were excluded to avoid skewing the research towards specific diagnostic labels.

\subsection{Country Analysis}

In order to examine the distribution of publications around the world, an R (R-core base version 4.0.0.) script (involving the libraries "stringr" [45] and "tidyverse" [46]) was used to extract the country's name from the last author's affiliation string of each publication. The choice to select the country from the last author's affiliation was taken because the last author in most cases tended to be the principal investigator of the research. Two $\mathrm{R}$ libraries (specifically "rworldmap" [47] and "RColorBrewer" [48]) were subsequently adopted for the design of the world map, in which, with different colours, we represented the number of publications linked to the specific country. During the country name extraction, some meaningless strings were obtained and were therefore discarded. These strings were meaningless for errors or inconsistencies within the registered affiliation strings. Other countries' names were converted manually when possible.

\subsection{Document Co-Citation Analysis}

For the scientometric analysis, all the keywords indexing the publications were collected. Specifically, a number of 37,364 keywords with frequencies ranging from 1 to 12,632 (a value that corresponded to the keyword "female") was extracted. All the keywords with frequency of appearance lower than 10 were, at this point, excluded from further analysis $(n=33,044$ keywords). In relation to the topic they represented, the eligible keywords (n $=4,320$ ) were inductively classified in broader categories with a qualitative approach by 5 independent coders. Subsequently, the classification's reliability was assessed by two independent supervisors, with a number of corrections that was lower than the $1.00 \%$ - making the inter-coders' reliability higher than $99.00 \%$. Eventually, this procedure resulted in the identification of 28 categories - namely, "Caregiver", "Education", "Environment", "Family", "Government", "Interpersonal relations", "Parenting", "Risk factor", "Socio-cultural factors", "Assessment", "Classification", "Demographic", "Development \& Prognosis", "Epidemiology", "Symptoms \& Behaviour", "Treatment \& Management", "Country", "Methods", "Scientific discipline", "Type of article", "Type of study", "Body", "Etiology", 
"Genetic risk", "Genetics", "Physiological risk", "Physiology", "Pregnancy". Following the same inductive procedure, these 28 clusters of keywords were subsequently grouped in four different areas, regarding the perspective they represented in the study of developmental disabilities: "Environmental Factors" ( $\mathrm{N}=324)$, "Physiological Factors" $(\mathrm{N}=1,021)$, "Expression of the disorder" ( $\mathrm{N}=2,400)$ and "How it is studied" $(\mathrm{N}=575)$. The first two macro areas - Environmental Factors and Physiological Factors - emerged from grouping the keywords that referred to terms that are typically considered as being part of the environmental and physiological factors respectively. Examples of those keywords for "Environmental Factors" are "maternal deprivation", "sibiling relations", "family functioning", and "early life stress"; for "Physiological Factors", example of keywords are "sex factors", "genetic predisposition to disease", and "preterm infant". On the other hand, the area "Expression of the disorder" emerged from a set of keywords that referred to the assessment and the symptoms of developmental disabilities. Examples of such keywords are "early diagnosis", "developmental screening", "developmental disorder", "autism", "brain development", and "Babinski reflex". Last, the area "How it is studied" included all the keywords referring to methodological aspects and terms, such as "cohort study", "controlled study", "interview", and "prospective study". The publications collected from Scopus were divided and clustered into their areas, according to their keywords, following the PRISMA approach (see Figure 11). At this point, we used CiteSpace software (version 5.7.R2) in order to run a document cocitation analysis (DCA) for each of the four identified areas. The document co-citation method allows one to examine the frequency in which multiple documents have been cited together (or co-cited) by subsequent documents. Thus, the network generated with the DCA depends on both citing - the ones downloaded directly from Scopus - and cited documents. In this way, thematic domains in the scientific landscape emerge automatically in a datadriven fashion in the form of clusters of cited and citing documents [49]. In all the CiteSpace DCAs, we adopted the TOP N node selection criteria, which creates a network by selecting the $\mathrm{N}$ most cited documents from each temporal slice among the data pool [50. Specifically, we chose TOP N $=10$ for all the four macro-areas of our interest. This value was chosen following the recommendations by Chen [51], where reliable networks would have a number of "7-10 major clusters with 10 or more members and each of the clusters has high silhouette values (e.g. $>0,70) "$. Structural and temporal metrics were subsequently used to examine the final networks. Specifically, 
among the structural metrics, we outputted the silhouette score, the modularity Q and the betweenness centrality. The silhouette metric indicates the inner homogeneity of a cluster [51] and ranges between -1 and 1; when its value is high, the cluster can be considered internally consistent as well as distinct from other clusters [51]. The modularity $\mathrm{Q}$ index, instead, is a metric which ranges from 0 to 1 and indicates the extent to which the network is divisible into modules [50, 51]. A high value for the modularity $\mathrm{Q}$ metric would indicate that clusters within the network are easily separable from one another. Lastly, for the structural metrics, betweenness centrality indicates, for each node, the extent to which the node (i.e., publication in the network) connects otherwise separate nodes in the network [52, 50]. In other words, high values in the betweenness centrality metric indicates a crucial role for the specific document within the network. Using Kuhn's philosophical view [53], groundbreaking publications are potentially defined by a high betweenness centrality because of their role in changing the trends and the interests of the "normal science" of their times and connecting it with a different group of researches. The temporal metric employed in this study was the citation burstness, which refers to a sudden increase of the number of citations for a specific node in the network [51]. Structural and temporal metrics, specifically betweenness centrality and citation burstness, are combined in order to obtain sigma indicator, whose values range from 0 to 1 [51], with higher values indicating a higher likelihood of research impact and innovation.

\section{Results}

\subsection{Country Analysis}

The results of the country analysis conducted using $\mathrm{R}$ software are displayed in Figure 2. The obtained picture represents the number of publications regarding developmental disabilities for each country of the world. In the map, we used different colours on a logarithmic scale in order to indicate the amount of papers linked to the specific country. Publication frequencies among countries range from 1 to 4,581. The map reports that, in the past century, the study of developmental disabilities has interested the majority of the countries in the world, highlighting the importance of this field of research again. A massive role in the study of developmental disabilities is played by North America. As it is reported in the map, the four countries leading the area of research in the world are all anglophones: the United 


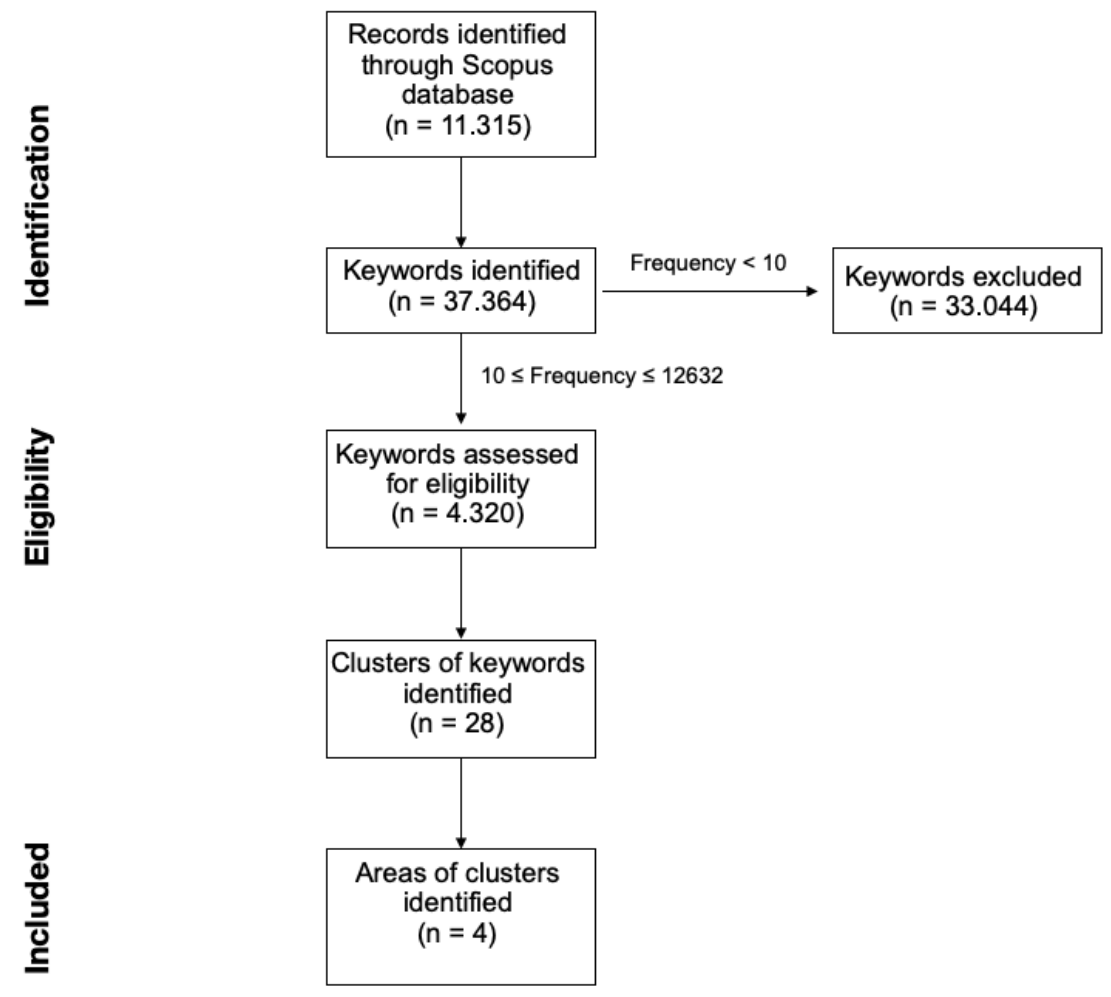

Figure 1: PRISMA diagram for the identification of the four main areas in the literature regarding developmental disabilities.

States $(\mathrm{n}=4,581)$, followed by the United Kingdom $(\mathrm{n}=1,257)$, Canada ( $\mathrm{n}$ $=658)$ and Australia $(\mathrm{n}=555)$.

\subsection{Expression of the disorder}

The first area of research we identified in our keywords analysis was "Expression of the disorder". Starting from 11,045 qualified references published between 1956 and 2020, the resulting network computed with the DCA consisted in 597 nodes and 1,535 links, showing a modularity Q index of 0.9043 and a weighted mean silhouette of 0.9712 . These values indicate that the network is highly divisible into modules and that, on average, these modules have a high extent of inner coherence.

The largest cluster in the network, cluster \#0, included 61 nodes and, therefore, covered the $10.21 \%$ of the network. This cluster had a high sil- 


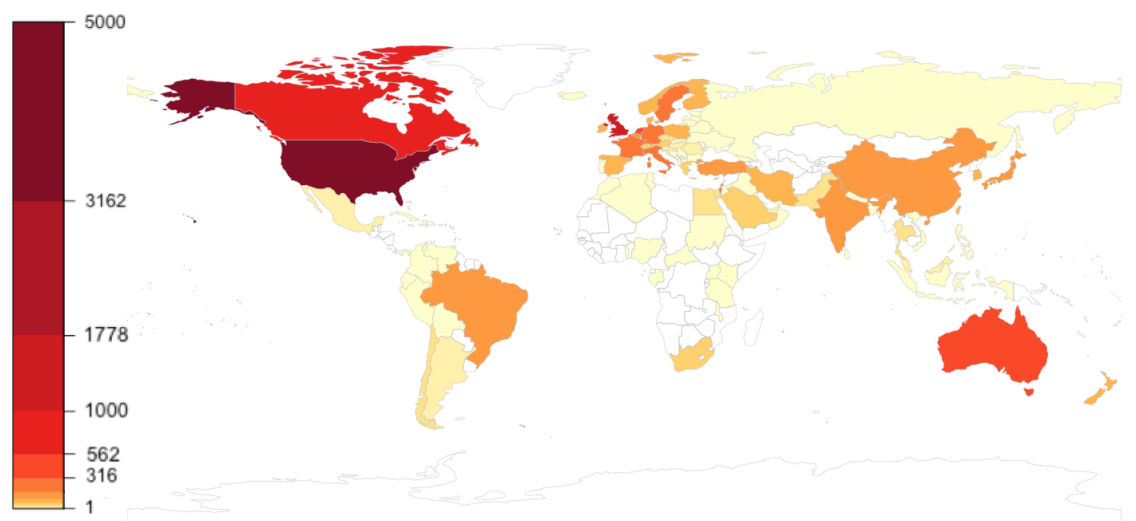

Figure 2: Frequencies of publications regarding developmental disabilities around the world

houette of 0.95 and 1993 was the year in which the publications were, on average, published. The second largest cluster, cluster \#1, had a size of 56 references (representing the $9.38 \%$ of the network) and a silhouette of 0.956 . 2008 was the mean year of publication. An amount of 42 nodes $(7.04 \%$ of the network) were gathered together forming cluster \#2. The silhouette value for this cluster was 0.962 and the nodes, on average, had a publication year corresponding to 2013. Therefore, regarding the topic of the nodes, this cluster was highly consistent and, regarding the mean year of publication, could be considered as a recent view on the study of developmental disabilities. Cluster \#4, at the end, included 29 references (representing the $4.86 \%$ of the number of nodes in the network) and showed a silhouette of 1 with 1998 as a mean year of publication. Given the silhouette values of these clusters, we can therefore consider them as strongly internally consistent.

Table 1 reports the 15 strongest citation bursts computed using the DCA on "Expression of the disorder". It emerged that 54 references among the network had a burst on their history. It is notable that the 4 references with the strongest burst belonged to cluster \#2. Specifically, the publication by Boyle et al. 29] had the strongest burst of the network, with a strength of 26.63 , and the one which lasted the longest, with a span of 7 years. Among other clusters, Simonoff et al. [54] (cluster \#1) had a publications in 2008 


\begin{tabular}{lccccccc}
\hline \multicolumn{1}{c}{ Reference } & Strength of burstness & Year & Beginning of burstness & End of burstness & Burst duration & Sigma & Centrality \\
\hline Boyle et al. [29] & 26.63 & 2011 & 2013 & 2020 & 7 & 12.87 & 0.10 \\
Association et al. [55] & 23.30 & 2013 & 2017 & 2020 & 3 & 1.05 & 0.00 \\
Richards et al. [56] & 22.94 & 2015 & 2017 & 2020 & 3 & 1.34 & 0.01 \\
Lek et al. [57] & 17.93 & 2016 & 2017 & 2020 & 3 & 1.14 & 0.01 \\
Simonoff et al. [54] & 15.80 & 2008 & 2010 & 2015 & 5 & 2.86 & 0.07 \\
Caspi et al. [58] & 15.32 & 2003 & 2006 & 2011 & 5 & 1.03 & 0.00 \\
Caspi et al. [59] & 15.21 & 2002 & 2005 & 2010 & 5 & 3.11 & 0.08 \\
Baker et al. [60] & 15.15 & 2002 & 2004 & 2010 & 6 & 1.55 & 0.03 \\
Baker et al. [61] & 13.86 & 2003 & 2007 & 2011 & 4 & 2.59 & 0.07 \\
Marshall et al. [62] & 12.66 & 2008 & 2010 & 2012 & 2 & 1.15 & 0.01 \\
Fraser et al. [63] & 11.81 & 2013 & 2017 & 2012 & 3 & 1.08 & 0.01 \\
Sebat et al. [64] & 11.54 & 2007 & 2009 & 2014 & 3 & 1.13 & 0.01 \\
Hallmayer et al. 65] & 11.18 & 2011 & 2013 & 2016 & 5 & 1.46 & 0.03 \\
Pinto et al. [66] & 10.40 & 2010 & 2011 & 2014 & 1.17 & 0.02 \\
Sanders et al. [67] & 10.00 & 2012 & 2013 & & & 1.27 & 0.02 \\
\hline
\end{tabular}

Table 1: Sample of publications with high citation burstness metrics generated in the DCA for Expression of the disorder

with a citation burst of 15.8 and a duration of 5 years and A. Caspi (cluster \#4) had two researches, published in 2003 and 2002, respectively with a citation burst of 15.33 and 15.21, both having a span of 5 years. All these publications with high magnitude regarding the citation burst can be considered as milestones in the study of developmental disabilities and parenting.

From table 2, which represents the 10 references with the highest values for betweenness centrality and the 10 with the strongest magnitude of sigma metric, the three references with the highest value of betweenness centrality were Risch et al. [68, Chakrabarti and Fombonne [69] and Piven et al. [70], all corresponding to 0.23 . Moreover, the work by Risch et al. [68] and by Chakrabarti and Fombonne [69], both belonging to cluster \#6, showed high centrality and high sigma values, being among the three references with the highest magnitude for each parameter of interest. In particular, they showed sigma values of 6.47 and 4.16 respectively.

\subsection{Physiological Factors}

The second area, labelled as "Physiological Factors", consisted in 9,928 qualified Scopus references published from 1962 to 2020. By computing a DCA, an amount of 646 nodes connected by 1,697 links defined the final network, which, by structural metrics, was described as highly divisible into modules, each of which was, on average, highly homogeneous (modularity Q index $=0.9155$; weighted mean silhouette $=0.9645$ ).

Examining the clusters configuration among the references forming the network, it was reported that the $7.59 \%$ of the total number of nodes was covered by cluster \#1, which had a size of 49 publications highly consistent 


\begin{tabular}{lcc}
\hline \multicolumn{1}{c}{ Reference } & Centrality & Cluster \\
\hline Risch et al. [68] & 0.23 & 6 \\
Chakrabarti and Fombonne [69] & 0.23 & 6 \\
Piven et al. [70] & 0.23 & 0 \\
Zwaigenbaum et al. [71] & 0.17 & 1 \\
Baron-Cohen et al. [72] & 0.16 & 0 \\
Boyle et al. [29] & 0.10 & 2 \\
on DSM-IV. [73] & 0.10 & 0 \\
Kramlinger and Post [74] & 0.09 & 18 \\
Plotsky and Meaney [75] & 0.09 & 0 \\
Caspi et al. [59] & 0.08 & 4 \\
\hline \multicolumn{1}{c}{ Reference } & Sigma & Cluster \\
\hline Boyle et al. [29] & 12.87 & 2 \\
Risch et al. [68] & 6.47 & 6 \\
Chakrabarti and Fombonne [69] & 4.16 & 6 \\
Zwaigenbaum et al. [71] & 3.23 & 1 \\
Caspi et al. [59] & 3.11 & 4 \\
Simonoff et al. [54] & 2.86 & 1 \\
Baker et al. [61] & 2.59 & 12 \\
on DSM-IV. [73] & 1.74 & 0 \\
Abbeduto et al. [76] & 1.55 & 12 \\
Baker et al. [60] & 1.55 & 12 \\
\hline
\end{tabular}

Table 2: Centrality and sigma computed via DCA for Expression of the disorder

with each other (silhouette: $=0.972$ ). On average, the papers forming this cluster were published in 2000. Thus, cluster \#1 included references positioning across the second and the third millennium. Cluster \#2, with its 44 nodes $(6.81 \%$ of the network), was the second largest group of references in the network. The silhouette value for this cluster corresponded to 0.94 and, on average, its references were published quite recently, in $2012.5 .88 \%$ of the nodes $(\mathrm{N}=38)$ gathered forming cluster \#3, which showed a silhouette of 0.95. For this cluster 2007 was the year in which, on average, the references were published. Last, cluster \#4 had a similar size of cluster \#3, with 37 nodes $(5.73 \%)$ and, on the other hand, a higher silhouette value of 0.974 . Cluster \#4 was the "youngest" major cluster of the network, having 2015 as the mean year of publication. 


\begin{tabular}{|c|c|c|c|c|c|c|c|}
\hline Reference & Strength of burstness & Year & Beginning of burstness & End of burstness & Burst duration & Sigma & Centrality \\
\hline Boyle et al. [29] & 24.42 & 2011 & 2013 & 2018 & 5 & 8.01 & 0.09 \\
\hline Richards et al. [56] & 22.89 & 2015 & 2016 & 2020 & 4 & 2.10 & 0.03 \\
\hline Lek et al. [57] & 17.01 & 2016 & 2017 & 2020 & 3 & 1.13 & 0.01 \\
\hline Caspi et al. [59] & 15.50 & 2002 & 2005 & 2010 & 5 & 2.61 & 0.06 \\
\hline Marshall et al. 62] & 14.11 & 2008 & 2009 & 2012 & 3 & 1.75 & 0.04 \\
\hline O'Roak et al. 80] & 13.74 & 2012 & 2014 & 2016 & 2 & 1.16 & 0.01 \\
\hline Caspi et al. 58 & 12.56 & 2003 & 2006 & 2011 & 5 & 1.09 & 0.01 \\
\hline $\mathrm{Li}$ and Durbin 81 & 12.11 & 2009 & 2012 & 2016 & 4 & 1.46 & 0.03 \\
\hline Baker et al. 60] & 11.95 & 2002 & 2007 & 2010 & 3 & 1.00 & 0.00 \\
\hline Association et al. 55] & 11.62 & 2013 & 2018 & 2020 & 2 & 1.60 & 0.04 \\
\hline Fraser et al. 63] & 11.53 & 2013 & 2017 & 2020 & 3 & 1.00 & 0.00 \\
\hline Sebat et al. 64 & 11.37 & 2007 & 2009 & 2012 & 3 & 1.36 & 0.03 \\
\hline Baker et al. 61 & 11.10 & 2003 & 2007 & 2011 & 4 & 1.36 & 0.03 \\
\hline Pinto et al. 66 & 10.67 & 2010 & 2011 & 2016 & 5 & 1.12 & 0.01 \\
\hline Hallmayer et al. 65 & 10.54 & 2011 & 2013 & 2014 & 1 & 1.62 & 0.05 \\
\hline
\end{tabular}

Table 3: Sample of publications with high citation burstness metrics generated in the DCA for Physiological Factors

55 nodes showed a citation burst in the area regarding "Physiological Factors". References reported in Table 3 are the 15 with the strongest magnitude of burst. It is notable that, also in this cluster, the reference with the strongest citation burst among the network, with a value of 24.42 , was authored by Boyle et al. [29]. When considering the duration of burstness, Zwaigenbaum et al. [71] (strength of burstness $=7.35$ ) was the node with the longest timespan, which corresponded to 6 years. Several references had a burst duration of 5 years: Boyle et al. [29], Caspi et al. [59] (strength of burstness $=15.50$ ), Caspi et al. [58] (strength of burstness $=12.56$ ), Pinto et al. [66] (strength of burstness $=10.67$ ), Rauch et al. [77] (strength of burstness $=$ 9.35), Fombonne [78] (strength of burstness $=5.05$ ), Glascoe [79] (strength of burstness $=4.28$ ) and Chakrabarti and Fombonne 69] (strength of burstness $=4.18$ ).

Table 4 shows the 10 references with highest values of betweenness centrality or sigma metrics. Specifically, the works by Zwaigenbaum et al. [71] (centrality $=0.12$; sigma $=2.36$ ) and Boyle et al. 29] (centrality $=0.09$; sigma $=8.01)$ appeared in both sections of the table among the three references with the strongest magnitude for the metric considered. Therefore, these two publications were highly influential in the field of developmental disabilities and also introduced scientific novelties in this area of research.

\subsection{How it is studied}

The third area obtained with the qualitative clustering of keywords was "How it is studied". For the DCA, the eligible publications indexed using these keywords were 10,513 and they were published between 1956 and 2020. 


\begin{tabular}{lcc}
\hline \multicolumn{1}{c}{ Reference } & Centrality & Cluster \\
\hline Zwaigenbaum et al. [71] & 0.12 & 2 \\
Chakrabarti and Fombonne [69] & 0.10 & 1 \\
Boyle et al. [29] & 0.09 & 2 \\
Lefebvre et al. [82] & 0.09 & 8 \\
Auranen et al. [83] & 0.09 & 8 \\
Baio et al. [84] & 0.08 & 4 \\
Fombonne [78] & 0.07 & 1 \\
Fombonne [85] & 0.07 & 1 \\
Caspi et al. [59] & 0.06 & 12 \\
Sand et al. [86] & 0.06 & 1 \\
\hline \multicolumn{1}{c}{ Reference } & Sigma & Cluster \\
\hline Boyle et al. [29] & 8.01 & 2 \\
Caspi et al. [59] & 2.61 & 12 \\
Zwaigenbaum et al. [71] & 2.36 & 2 \\
Richards et al. [56] & 2.10 & 2 \\
Marshall et al. [62] & 1.75 & 3 \\
Hallmayer et al. [65] & 1.62 & 2 \\
Association et al. [55] & 1.60 & 4 \\
Chakrabarti and Fombonne [69] & 1.48 & 1 \\
Li and Durbin [81] & 1.46 & 2 \\
Rauch et al. [77] & 1.45 & 2 \\
\hline
\end{tabular}

Table 4: Centrality and sigma computed via DCA for Physiological Factors

CiteSpace computed a network formed by 658 nodes connected with each other by 1,755 links and with modularity $\mathrm{Q}$ index and weighted mean silhouette of 0.8953 and 0.9678 respectively. These values indicate a network highly divisible into highly homogeneous clusters.

In this macro-area of research, cluster \#0, the biggest one of the network, was a group of 70 nodes ( $10.64 \%$ of the network) highly related with each other (silhouette $=0.912$ ). The publications grouped in this cluster were on average published in 2008, allowing us to consider this as a recent area of research. Cluster \#1 consisted, instead, of 54 nodes (covering the $8.21 \%$ of the network) having a silhouette value of 0.953 and 1993 as the mean year of publication. Given the year that on average the references were published, this cluster is the oldest one in the first four clusters. Cluster \#2 with a size 


\begin{tabular}{|c|c|c|c|c|c|c|c|}
\hline Reference & Strength of burstness & Year & Beginning of burstness & End of burstness & Burst duration & Sigma & Centrality \\
\hline Boyle et al. [29] & 24.90 & 2011 & 2013 & 2020 & 7 & 110.03 & 0.21 \\
\hline Richards et al. [56] & 23.08 & 2015 & 2016 & 2020 & 4 & 2.80 & 0.05 \\
\hline Lek et al. [57] & 16.81 & 2016 & 2017 & 2020 & 3 & 1.05 & 0.00 \\
\hline Caspi et al. [59] & 16.31 & 2002 & 2005 & 2010 & 5 & 1.93 & 0.04 \\
\hline Simonoff et al. 54 & 16.00 & 2008 & 2010 & 2015 & 5 & 1.93 & 0.04 \\
\hline Association et al. 55] & 15.35 & 2013 & 2018 & 2020 & 2 & 1.00 & 0.00 \\
\hline Caspi et al. 58 & 14.34 & 2003 & 2006 & 2009 & 3 & 1.33 & 0.02 \\
\hline Marshall et al. 62 & 13.94 & 2008 & 2009 & 2012 & 3 & 1.30 & 0.02 \\
\hline O'Roak et al. 80 & 13.80 & 2012 & 2014 & 2016 & 2 & 1.18 & 0.01 \\
\hline Adzhubei et al. 87 & 13.25 & 2010 & 2013 & 2018 & 5 & 1.10 & 0.01 \\
\hline Baker et al. 61$]$ & 13.11 & 2003 & 2004 & 2011 & 7 & 1.32 & 0.02 \\
\hline Fraser et al. 63. & 12.13 & 2013 & 2017 & 2020 & 3 & 1.08 & 0.01 \\
\hline Baker et al. 60 & 11.74 & 2002 & 2004 & 2010 & 6 & 1.05 & 0.00 \\
\hline Hallmayer et al. 65 & 11.48 & 2011 & 2013 & 2014 & 1 & 1.34 & 0.03 \\
\hline Sebat et al. 64] & 11.23 & 2007 & 2009 & 2012 & 3 & 1.16 & 0.01 \\
\hline
\end{tabular}

Table 5: Sample of publications with high citation burstness metrics generated in the DCA for How it is studied

of 45 nodes represented the $6.84 \%$ of the network. This cluster showed a high silhouette value of 1 and a recent temporal location with 2015 as its mean year of publication. Lastly, cluster \#3 was composed by 33 nodes highly consistent with each other (silhouette value $=0.995)$ and a mean publication year corresponding to 1999 .

For "How it it studied", 65 nodes in the network showed a citation burst (see Table 5 in which the 15 references with the strongest citation burst are reported). It is relevant that, among the 10 publications with the highest burst magnitude, 4 belonged to cluster \#5. Specifically, the first authors of these references are, in order of strength, Richards et al. [56] (strength of burstness $=23.08$ ), Lek et al. [57] (strength of burstness = 16.81), O'Roak et al. 80. (strength of burstness = 13.80) and Adzhubei et al. 87] (strength of burstness $=13.25$ ). Not only the work by Boyle et al. [29] was the one with the strongest burst bit also the one with the longest burst duration (having a span of 7 years, as the node by Baker et al. [61]).

Table 6 reports the references with the highest values of betweenness centrality and sigma (specifically, the top 10 references for each metric). As for the previous cluster, the works by Zwaigenbaum et al. [71] (centrality $=0.25$; sigma $=5.54$ ) and Boyle et al. [29] (centrality $=0.21$; sigma $=110.03$ ) resulted as influential and innovative papers for their times. Specifically, the publication by Boyle et al. [29] had the highest sigma value among the network, almost 20 times bigger than the one computed for the second reference cited in the table. Other references that appeared in both sections of the table were the ones authored by Baird et al. 88] (centrality $=0.22$; sigma $=2.49$ ), on DSM-IV. [73] (centrality $=0.13$; sigma $=2.11$ ) and Chakrabarti 


\begin{tabular}{lcc}
\hline \multicolumn{1}{c}{ Reference } & Centrality & Cluster \\
\hline Zwaigenbaum et al. [71] & 0.25 & 0 \\
Baird et al. [88] & 0.22 & 8 \\
Boyle et al. [29] & 0.21 & 0 \\
Osterling and Dawson [89] & 0.21 & 15 \\
Baron-Cohen et al. [72] & 0.16 & 1 \\
on DSM-IV. [73] & 0.13 & 1 \\
Chakrabarti and Fombonne [69] & 0.09 & 8 \\
Rutter et al. [90] & 0.09 & 3 \\
Dawson [91] & 0.09 & 0 \\
Kramlinger and Post [74] & 0.09 & 15 \\
\hline \multicolumn{1}{c}{ Reference } & Sigma & Cluster \\
\hline Boyle et al. [29] & 110.03 & 0 \\
Zwaigenbaum et al. [71] & 5.54 & 0 \\
Richards et al. [56] & 2.80 & 5 \\
Baird et al. [88] & 2.49 & 8 \\
on DSM-IV. [73] & 2.11 & 1 \\
Simonoff et al. [54] & 1.93 & 0 \\
Caspi et al. [59] & 1.93 & 3 \\
Chakrabarti and Fombonne [69] & 1.84 & 8 \\
Risch et al. [68] & 1.73 & 8 \\
Trouton et al. [92] & 1.55 & 3 \\
\hline
\end{tabular}

Table 6: Centrality and sigma computed via DCA for How it is studied

and Fombonne [69] (centrality $=0.09 ;$ sigma $=1.84)$.

\subsection{Environmental Factors}

The last area of interest, "Environmental factors", was delineated by a number of 9,541 qualified Scopus references published between 1964 and 2020. The TOP $\mathrm{N}=10$ criteria created a network composed by 622 nodes with 1,498 connections. The final network showed a modularity Q index of 0.9014 and weighted mean silhouette of 0.9581 . Considering these two metrics, the network was highly divisible into modules that, on average, were highly consistent.

Examining the clusters configuration underlying the macro-area, we could observe that cluster \#0, the largest one with a size of 47 nodes, covered the 
$7.56 \%$ of "Environmental Factors". Furthermore, this cluster resulted to have a silhouette index of 0.966 and a mean year of 2009. Cluster \#1 and cluster \#2 had a mean year of publication placed in the past century (1997, 1996, respectively). The second largest group of nodes, cluster \#1, consisted in a gathering of 41 references (6.59\% of the network) with a good consistency (silhouette $=0.89$ ). Cluster \#2 was formed by 35 nodes highly consistent with each other (silhouette $=0.938$ ). This cluster had a coverage of $5.63 \%$ of the network and it could be considered as the oldest one among the four largest clusters of the network. Finally, cluster \#3, with a size of 31 nodes consisted in the $4.98 \%$ of the network. The silhouette value, specifically 0.997, for this cluster was high, indexing a high inner consistency for the cluster. 2014 was the year in which, on average, the references of this cluster were published. Hence, among the four largest clusters, cluster \#3 was the youngest one.

Among the 55 references with a citation burst, table 7 reports 15 of them. Overall, it is relevant that 19 references over the 55 with a citation burst belonged to cluster \#0, which, despite being quite recent, was highly influential in the study of the environmental factors of developmental disabilities and parenting. Specifically, the work by Boyle et al. 29] was, once again, the one with the highest magnitude of citation burst in the network, with a strength of 26.57. Its timespan of 5 years was the second longest burst duration after the publication authored by Zwaigenbaum et al. [71, which showed a burst duration of 6 years and a strength of 7.47. Within the network, other references had their burst spanning for 5 years. Specifically, ordered by strength of burstness, these references were authored by: Caspi et al. [59] (strength of burstness $=15.58$ ), Caspi et al. [58] (strength of burstness = 13.35), Adzhubei et al. [87] (strength of burstness = 11.91), Simonoff et al. [54 (strength of burstness $=10.34$ ), Glascoe [79] (strength of burstness $=$ 4.89) and Fombonne [78] (strength of burstness $=4.51$ ).

Table 8 shows references with highest betweenness centrality and highest sigma values. Specifically, the node with the highest value in regards of the centrality was authored by Hayes and Watson [96] (centrality $=0.20$ ). Similarly, high centrality values were obtained for the works by Chakrabarti and Fombonne 69] (centrality $=0.17$ ), which belonged to cluster \#1, Dawson et al. [97] (centrality $=0.16)$ and Zwaigenbaum et al. [71] (centrality $=0.15)$, both belonging to cluster $\# 0$. Considering sigma metric, the research by Boyle et al. 29] resulted to be the one with the highest value (sigma $=10.86)$. Therefore this reference represented a novelty in the study of developmental 


\begin{tabular}{|c|c|c|c|c|c|c|c|}
\hline Reference & Strength of burstness & Year & Beginning of burstness & End of burstness & Burst duration & Sigma & Centrality \\
\hline Boyle et al. [29] & 26.57 & 2011 & 2013 & 2018 & 5 & 10.86 & 0.09 \\
\hline Richards et al. 56] & 17.69 & 2015 & 2017 & 2020 & 3 & 1.69 & 0.03 \\
\hline Caspi et al. 59 & 15.58 & 2002 & 2005 & 2010 & 5 & 1.69 & 0.03 \\
\hline Association et al. 55] & 15.56 & 2013 & 2018 & 2020 & 2 & 1.00 & 0.00 \\
\hline Baker et al. 61] & 13.55 & 2003 & 2007 & 2011 & 4 & 5.84 & 0.14 \\
\hline Caspi et al. 5 & 13.35 & 2003 & 2006 & 2011 & 5 & 1.32 & 0.02 \\
\hline Marshall et al. 62 & 12.98 & 2008 & 2009 & 2012 & 3 & 1.30 & 0.02 \\
\hline Ozonoff et al. 93] & 12.08 & 2011 & 2014 & 2018 & 4 & 1.13 & 0.01 \\
\hline Adzhubei et al. 87 & 11.91 & 2010 & 2013 & 2018 & 5 & 1.03 & 0.00 \\
\hline Sebat et al. 64 & 11.34 & 2007 & 2009 & 2012 & 3 & 1.22 & 0.02 \\
\hline Baker et al. 60 & 11.32 & 2002 & 2007 & 2010 & 3 & 1.02 & 0.00 \\
\hline Fombonne 94 & 11.20 & 2009 & 2012 & 2014 & 2 & 1.41 & 0.03 \\
\hline Estes et al. 95 & 11.06 & 2009 & 2013 & 2015 & 2 & 1.38 & 0.03 \\
\hline Simonoff et al. 54 & 10.34 & 2008 & 2010 & 2015 & 5 & 1.45 & 0.04 \\
\hline Hallmayer et al. 65 & 10.07 & 2011 & 2013 & 2014 & 1 & 1.33 & 0.03 \\
\hline
\end{tabular}

Table 7: Sample of publications with high citation burstness metrics generated in the DCA for Environmental Factors

disabilities, as it was already reported in the other clusters.

\section{Discussion}

\subsection{Country Analysis}

Examining the distribution of articles across the world is important in order to analyse the areas interested in developmental disabilities with a focus on parenting in a socio-cultural perspective, with a good insight into where our knowledge comes from and how representative it is of the world surrounding us. What emerged from the country analysis was that the geographical distribution of publications resulted to be strongly centered on data provided by the four main anglophone countries of the world: the United States, the United Kingdom, Canada and Australia. Specifically, researchers working in North America have provided almost half of the analyzed publications. This is meaningful, for it indicates that a large majority of what we know today about developmental disabilities comes from a single country. Hence, the problem and challenge for future works is to understand the degree in which what we have learnt on developmental disabilities from studies conducted in North America is generalizable and applicable to the population living in the rest of the world. As a matter of fact, the results of the current paper are in line with the "WEIRD population problem". Indeed, as reported by Henrich et al. 25] and Nielsen et al. [100, psychology highly relies on data collected from Western, Educated, Industrialized, Rich and Democratic (WEIRD) societies. This becomes a problem if we consider that people from WEIRD societies are, using the words of Henrich and colleagues, "some of the most 


\begin{tabular}{lcc}
\hline \multicolumn{1}{c}{ Reference } & Centrality & Cluster \\
\hline Hayes and Watson [96] & 0.20 & 3 \\
Chakrabarti and Fombonne [69] & 0.17 & 1 \\
Dawson et al. [97] & 0.16 & 0 \\
Zwaigenbaum et al. [71] & 0.15 & 0 \\
Baker et al. [61] & 0.14 & 10 \\
Smedje et al. [98] & 0.13 & 10 \\
Johnson et al. [99] & 0.10 & 0 \\
Baio et al. [84] & 0.10 & 5 \\
Baird et al. [88] & 0.10 & 1 \\
Boyle et al. [29] & 0.09 & 0 \\
\hline \multicolumn{1}{c}{ Reference } & Sigma & Cluster \\
\hline Boyle et al. [29] & 10.86 & 0 \\
Baker et al. [61] & 5.84 & 10 \\
Hayes and Watson [96] & 5.39 & 3 \\
Zwaigenbaum et al. [71] & 2.81 & 0 \\
Chakrabarti and Fombonne [69] & 2.73 & 1 \\
Dawson et al. [97] & 2.52 & 0 \\
Risch et al. [68] & 1.88 & 1 \\
Johnson et al. [99] & 1.82 & 0 \\
Caspi et al. [59] & 1.69 & 14 \\
Richards et al. [56] & 1.69 & 15 \\
\hline
\end{tabular}

Table 8: Centrality and sigma computed via DCA for Environmental Factors

psychologically unusual people on Earth", for they represent the $12 \%$ of the world's population. Therefore, the reliance on data collected in WEIRD societies is linked to the under-representation of the rest of the world, especially for low- and middle-income countries.

The same applies to the study of developmental disabilities, a series of conditions with a complex etiology in which several genetic and environmental factors are involved. As a matter of fact, genetic causes of developmental disabilities show some variations across countries [101, 102]. For instance, in West African countries a relevant percentage of children is affected by inherited haemoglobinopathies which lead to an increased risk for health and development complications [103]. At the same time, environmental factors affecting the development are different across countries [102. For instance, 
in low- and middle-income countries, pregnant women are more likely to expose the fetus to imbalanced intake of macro- and micronutrient [104, 105], which in turn can affect the child's optimal development [106]. As for the nutritional intake, factors such as infections and environmental toxins (e.g., rubella, syphilis, HIV, polio) exposure, which can strongly impact the fetus development [107, 108, 109, shows variations across countries that can not be understood if looking uniquely to data coming from North America. For instance, in low-income countries of Africa, the main cause of disability is the exposure to infectious diseases, such as malaria, polio and leprosy [110]. Also, rubella is another infectious cause of disability and its exposure is more common in low-income countries than wealthier ones [111, 112].

By understanding these factors underlying developmental disabilities in low- and middle-income countries, more efficient screening and disorder's management practices would be guaranteed. This is especially important in light of the evidence indicating that prevalence rates of developmental disabilities seem to be higher in low-income countries when compared to wealthier ones [102]; and the same correlation is found if considering the socioeconomical status of the family within a specific country [113, 114].

In conclusion, researches aiming to examine the gaps in the existing literature in less explored population would be precious in order to better understand developmental disabilities under an idiographic, country- and culture-based approach. The single individual would be back at the center of the attention and considered as a complex result of the interaction between biological, social and psychological factors.

\subsection{Document Co-Citation Analysis}

In this section, the content of the most important clusters within each of the four identified macro-areas is summarized. For the overlap of documents between macro-areas, in each of the following sections, only the documents belonging to the major clusters and that were related to the specific macroarea were selected and presented $(\mathrm{N}=49$ for Expression of the disorder; $\mathrm{N}$ $=61$ for Physiological factors; $\mathrm{N}=61$ for How it is studied; $\mathrm{N}=39$ for Environmental factors). Moreover, clusters are presented in chronological order.

\subsubsection{Expression of the disorder}

"Expression of the disorder" refers to a group of researches where the focus is on the description of the disorders, whether for assessment or treat- 
ment/management purposes, as it emerges from the publication by Beitchman et al. [115], which was among the major citers of the cluster. Cluster \#0 consisted in publications aiming to describe disorders with difficulties in communication, such as language disorders in particular, but also autism spectrum disorders (as testified by the publication of Howlin et al. [116], which was the major citer node in the cluster). For both classes of disorders, the cluster included publications which aimed to implement new assessment opportunities. In fact, part of the scientists interested in understanding autism have focused their work on the early detection of the disorder. Particularly, Baron-Cohen et al. [72] showed the possibility of the early detection of autism in 18-month-old toddlers, thanks to the development of the Checklist for Autism in Toddlers (CHAT). Osterling and Dawson [89, during the same years, used home videotapes in order to identifying atypical behaviours in autistic 1-year-old children. On the other hand, for what regards specific language impairment, the publication authored by Tomblin et al. [117] focused on developing a system (the EpiSLI) allowing the diagnosis of the disorder in kindergarten children. As a matter of fact, from what it is reported in the network, the interest on language disorders also branched towards the description of development of the disorder. Studies in the network focusing on this topic were mainly authored by H.W. Catts and J.H. Beitchman. Specifically, the former focused on showing a relationship between speech-language impairment in kindergarten and reading disabilities on the follow-up on first and second grades [118]. The latter, instead, authored three works, in which follow ups were conducted in order to assess the outcomes in speech and language-impaired children [119, 120, 121]. The second major citer in the cluster (the publication authored by Cohen et al. [122]) focused their attention on the social cognitive processing and psychiatric disorders in children with identified and unsuspected language impairments. Other relevant papers in the cluster focused on the management of the disorders. Specifically, for what concerns language impairment, Dale et al. [123], Hemmeter and Kaiser [124] and Girolametto et al. 125] explored the results for some intervention technique, such as parent-child book reading, milieu teaching and interactive focused stimulation. On the side of autism, Koegel et al. [126] addressed the problem of stress in mothers of autistic children.

Cluster \#4 consisted in publications exploring the Gene-Environment paradigm in order to understand normal and pathological behaviours. For what concerns the expression of the disorder, fewer works focused on the assessment of disorders. Specifically, these authors mainly analysed the efficacy 
of diagnostic instruments, such as the Rutter scales [127, The Strength and Difficulties Questionnaire [128] and the ASEBA Form [129].

A large amount of publications gathered together to form Cluster \#1 focused their attention on the genetic analysis of autism (as highlighted by some of the major citing publications [130, 131, 132]). For what regards the "Expression of the disorder", some works in the cluster have deepen the understanding of the epidemiology of developmental disabilities. In fact, this second cluster included works which aimed to study the distribution of autism spectrum disorders [133, 134, 135], attention deficit hyperactivity disorder [136] and/or other developmental disabilities [94]) across the world. In regards to the assessment and the diagnosis of the disorders, the studies of Zwaigenbaum et al. [71] and Johnson et al. 99] resulted to be central (as testified by their citation burst) for the study of autism, whereas, for developmental disabilities in general, a screening instrument (Bayley Scales of Infant and Toddler Development) was developed by Bayley [137. The presence of other disorders in patients with autism was also taken into account by other scientists. For instance, some of them focused their studies on the comorbidity of psychiatric disorders [54] or also other intellectual disabilities 138 on patients with autism. The importance of the work by Simonoff and collaborators (2008) is highlighted by the high citation burst detected for this reference. Finally, management of autism was considered by the publications of Osborne et al. [139, Dawson [91, Whittingham et al. 140], Dawson et al. [97, in which the authors examined the efficacy of different types of management or prevention of the disorder, such as the Early Start Denver Model (ESDM), early teaching interventions and the Stepping Stones Triple P.

Cluster \#2 had three main trends on the references that were composing it. First, the interest on the genetics underlying different developmental disabilities or psychiatric conditions (testified by the top citing nodes among the cluster [141, 142]). Second, the focus on the usefulness of the genetics diagnosis in several disorders. Third, the epidemiology of autism and developmental disabilities. Reserving the first point for the discussion regarding physiological risks, second and third trends deserve to be examined with a closer eye, for the role played by the development of the DSM-5 [55], which was the reference with the second largest citation burst among the network. As regards the assessment, some scientists reported the importance of a molecular analysis for the diagnosis of suspected genetic disorders [143, 144, 145, 146, 147]. The most important citing work within the cluster 148 focuses on the genomic diagnosis of children with intellectual disabilities and developmental 
delay. Furthermore, in relation to the introduction of DSM-5, Reilly et al. [149] analysed the exclusion of Specific Language Impairment from the new diagnostic manual. The third branch of researches in the cluster focused on studying the distribution of disorders across the world. In particular, the reference authored by Boyle et al. [29], Elsabbagh et al. [150] and Zablotsky et al. [151 focused on the prevalence of different developmental disabilities, whereas Kim et al. [152, Baio et al. 84 mainly concentrated their work on autism. The work authored by Boyle and collaborators (2011) had the largest citation burst of the network.

\subsubsection{Physiological factors}

"Physiological factors" is an area of research which, as suggested by the name, consists in the interest on different fields such as genetics, physiology, anatomy in order to investigate the underlying basis of typical and atypical behaviours. In particular, publications in cluster \#1 mainly focused on the physiological risk and the possible outcomes linked to low birth weight [153, 154, 155] or preterm birth [156, 157, 158, 159, 160]. In the study by Mercer et al. [161], which was among the major citing nodes of the cluster, parents of children with autism spectrum disorders were asked to report which in their opinion were the causes of the condition of their children. In general those parents reported a strong self-reported feeling of guilt for their children's condition, and the factors that they considered as causes of autism spectrum disorders were genetic influences, perinatal and prenatal factors, nutrition and also vaccines. As a matter of fact, the link between vaccines and autism spectrum disorders finds its origins from the retracted publication by Wakefield et al. [162, where a link between the triple vaccine for measles, mumps and rubella (MMR) and autism was presented. From the publication of this controversial article, scientists started to try replicating the results, without much success [163, 164, 165]. Autism itself was largely studied in the cluster and especially in regards to the concept of broader autism phenotype together with the heterogeneity in the manifestations of such condition [166, 70]. Moreover, Risch et al. 68, focused on the genetic causes underlying the disorder. This last work obtained the highest citation burst among the cluster.

Exploring the genetic risks underlying the development of autism spectrum disorders was also the main purpose of the major part of the references belonging to cluster \#3. In particular, autism's genetics has been described in the articles by Muhle et al. [167] and Abrahams and Geschwind [168]. As 
a matter of fact, researchers focused on the study of CNVs [64, 62, 169, 66] whereas some of them specifically looked at microdeletions and microduplications [170, 171, 172]. The interest towards the genetic of autism was accompanied by the exploration of the possible existing broader autism phenotype, with studies that found evidence it especially when examining fathers 173, 174. Globally, the works by Sebat et al. 64, Marshall et al. 62 and Pinto et al. 66] were highly relevant in the cluster, as reported by their high citation bursts.

References composing cluster \#2 were mainly centered on examining the genetic risk in several disorders, such as Cerebral Visual Impairment [175], X-linked intellectual disability [176], Rett syndrome [177] and autism spectrum disorders [178. Moreover, the genetic heritability in autism spectrum disorders was quantified in a twin study conducted by Hallmayer et al. 65]. Other group of researchers specifically focused on denovo mutations [179, 80, 67, 180, 181] or copy number variations (CNVs) [130, 182, 183, 184] underlying the same condition. Within the cluster, the genetic configuration of several disorders has been explored as well. In fact, the commentary by Insel et al. [185] expressed the appreciation of the scientific community towards a new way of classifying disorders, focusing more on pathophysiological criteria rather than the classical behavioral diagnostic categories. Following this trends of research, denovo mutations, which are mainly of paternal origin and whose number depends on paternal age [186], have been analysed in epileptic encephalopathies [187, 142], non-syndromic intellectual disability [77] and intellectual disabilities [144]. Conversely, copy number variations (CNVs) were studied in genomic disorders [188] and developmental delay [189]. Not only the interest within this cluster was focused on the underlying risks for the development of several developmental disabilities, for several tools and techniques were also described in order to help scientists and clinicians to conduct genetic analysis [81, 190, 191]. These techniques were explored in relation to the possibility of conducting genetic diagnosis of developmental disabilities (see the following citing references [192, 148]). Finally, an innovative model to explain psychopathology through the differential susceptibility to the environment was introduced by Belsky and Pluess [193] on the research domain of Gene-Environment interaction.

References in cluster \#4 did not focus on the investigation of the physiological etiology behind a specific disorder. Rather, some authors explored psychiatric outcomes in relation to specific physiological risks, such as preterm birth, parental age or maternal genetics [194, 195, 196]. 


\subsubsection{How it is studied}

In the network of "How it is studied", cluster \#1 did not consist in references in which authors specifically focused on one developmental disability. Rather, several clinical conditions were examined recurring to different methodologies. In particular, family and twin study designs were used in order to examine, for instance, the heritability of specific language impairment [197, 198, 199], developmental language disorder [200, 201], developmental dyslexia [202] and autism [203]. Moreover, longitudinal studies were run to deepen the comprehension of developmental trajectories [121, 204, 205] (see also the major citing document within the network [116]) and reviews [206, 207, 208, 209] were written in regards to several developmental disorders such as autism, speech and language delay and attention deficit disorder.

Cluster \#3, on the other hand, reported the emergency of Gene-byEnvironment study designs. As a matter of fact, these paradigms were used to explore the etiology not only in regards to developmental disabilities but for a wider range of disorders, allowing the researchers to take into account the interaction between genetic and environmental factors. For instance, Gene-by-Environment studies were used to explore the roots of antisocial behaviour [59], depression [58, 210, 211] and behavioural inhibition [212]. In particular, the study by Caspi et al. [59] had a high impact in the literature, as testified by its citation burst. This burst likely represents the novelty that the Gene-by-Environment paradigm also introduced in the study of developmental disabilities. As a matter of fact, this interest on the methodology emerges from a closer look on the citing documents within the cluster in which developmental disabilities, such as reading disability and attention deficit/hyperactivity disorder, are studied following this trend of research [213, 214]. As a matter of fact, the cluster includes reviews studying in depth the Gene-Environment approach [215] and its implication on the investigation of psychopathology [90].

From the analysis of the references composing cluster \#0 in the area of "How it is studied", it emerged that the focus was mainly on studying autism spectrum disorders in regards to their genetic basis. Specifically, this was achieved by using several methodologies, such as comparative genomic hybridization [64, 170, 172, 182], dense genotyping arrays [66], whole-exome sequencing [179, 67] and genome-wide analysis [169, 130]. Together with these techniques of analysis, the genetic heritability of autism has been explored using twin studies [135, 65], siblings studies [216, 93] and relatives 
studies in general (as for the major citing reference [173]). These studies, in which a recurrence of autism-like traits within families of patients with a diagnosis of autism is reported, are consistent with the concept of the broader autism phenotype. Cluster \#0 was not only composed by experimental studies. Rather, it consisted in several reviews that examined a specific aspect of developmental disabilities. For instance, some of these reviews focused on conditions such as autism [168, 217], ADHD [218, 136], specific language impairment [149] and pervasive developmental disorders [94].

In general, the references in cluster \#2 summarized the knowledge obtained from previous studies on developmental disabilities by recurring to literature [219, 220, 221] and systematic reviews, alongside meta-analysis [150, 96, 222, 223, 224, 225, 226, 227. Furthermore, in this study cohort study designs were adopted to study the consequences of an early gestational age [194], low birthweight [228], efficacy of oral cannabis extracts for treatment of refractory epilepsy [229], the tendency to vaccinate children in a lesser extent after they receive a diagnosis of autism spectrum disorder [230] and the effects of parental age on the risk across pediatric neuropsychiatric disorders [196].

\subsubsection{Environmental Factors}

In cluster \#2, stress profile among mothers of children with autism was studied by Koegel et al. [126]. With regards to the same condition, Bailey et al. 203] conducted a twin study in which the main focus was to understand the genetic causes underlying autism. Specifically, the authors suggested that obstetric hazards should be considered as consequences of genetically influenced abnormal development rather than independent etiological factors. Other environmental influences in the etilology of developmental disabilities were analyzed within the cluster. For instance, Milberger et al. 231 reported that maternal smoking during pregnancy conferred a particular risk towards attention deficit hyperactivity disorder. At the same time, a correlation between alcohol exposure in uterus and attention deficit hyperactivity disorder and autism was reported in the article by Aronson et al. [232.

Stress in parents of children having one of three specific developmental disabilities (i.e., fragile-X, Prader-Willi and Williams-Beuren syndrome) was examined in cluster \#1 by Sarimski [233]. Furthermore, among the network, specific environmental factors were studied in order to better understand typical and atypical development. For instance, Bolton et al. [166] focused on the role of obstetric complications on the outcomes autism spectrum disor- 
ders, whereas, although not focusing on a disability, Plotsky and Meaney [75] studied the link between early maternal separation and stress responsiveness in rats.

The analysis of environmental factors in cluster \#0 included the concept of differential-susceptibility for psychopathology. Differential-susceptibility has been widely studied by Belsky and Pluess [193] and it refers to the idea that some individuals, which are carriers of "plastic genes", are not only more vulnerable than others in front of adverse events, but they could also benefit the presence of supportive and enriching experiences. In the framework of Gene-by-Environment interplay in psychopathology, Hicks et al. 234] investigated the emergence of externalising disorders and identified several environmental risk factors. Within this cluster, the interest towards genetic factors underlying several developmental disabilities is well represented when analysing the citing nodes [184, 235, 236] together with the interest towards environmental factors [237. For instance, in regards to autism, Grabrucker 238] identified in the immune system disruptions and in the zinc homeostasis two factors that potentially could impact synaptic transmission. Alongside these works, several researches addressed the link between parental mental health and developmental disabilities on the offspring. In particular, parents of children with autism spectrum disorders and/or developmental disabilities showed to have an increased risk regarding their mental health and their family functioning [239, 240, 241, 242, 243, 95]. In fact, the study by Dardas and Ahmad [244], which is among the major citers in the cluster, highlighted the need to provide care also to parents of children with autism for their role as caregivers. As their citation bursts point out, the works by Herring et al. [239], Mandell et al. [245] and Estes et al. [95] were relevant within the network.

References in cluster \#3 studied the relationship between developmental disabilities and parental stress. For instance, Neece et al. [246] showed the bidirectional influences existing between parental stress and behavioral problems in both typically and atypically developed children. In other words, they showed that parental stress and children behavioral problems have a mutual influence on each other. In regards to developmental disabilities, some references showed the negative impact that some of these conditions have on parental stress and family functioning [247, 96]. Conversely, other references have showed the risk for the child with a developmental disability to live in conditions of unsupportive parenting [248]. For this reason, studies have provided insight into the need of developing programs aimed to support these 
families [249, 250, 251, 252, 253, 254, 255, for instance by considering the protective role of having a supportive partner [256, 257]. In regards to the experience of caregivers of children with intellectual disabilities, the reviews by Marsh et al. [258] and by Hu [259] provided insight into the role of fathers.

\section{Limitations}

Some limitations need to be taken into account when interpreting the presented results. First of all, the sample of publications collected in order to conduct this study was derived uniquely from one platform, Scopus. Future research should try to explore whether the patterns observed in the literature vary across database platforms. Secondly, the country analysis was based on the country within the last author's affiliation string. If this in most cases reflects the affiliation of the principal investigator, there could be a bias in which data collections conducted in a country that was different from the last author's affiliation would not be well represented in the map of the present study. Another aspect that is worth noting in regards to the country analysis is that it originated from the research on Scopus where only the publications written in English language were selected. This, on one side, is a strength for it gives a standardized and rigorous way to consider uniquely the international scientific literature on the field. Nevertheless, some important publications written in other languages may have been excluded from the research and from the country analysis. It is to note, though, that the vast majority of publications that results with the string "TITLE-ABS-KEY ( parent* AND ( development* AND disorder* OR intellectual AND disab* OR genetic* OR neurodev* ))" are written in English. Thus, even if the contribution of other countries may have been slightly underrepresented, the results can be considered as representative of the scientific panorama on developmental disabilities research. Another limitation derives from the fact that the method we used for clustering the papers into the four main areas largely depended on the keywords used to index a document. Publications usually have more than one keywords, some of which are very general. This brought us to have a large overlap of papers that composed the four macro areas. Finally, the scientometric approach is strongly grounded on the patterns of citations between documents. As a matter of fact, this approach focuses only on a quantitative evaluation of these patterns while not considering the reasons behind them (e.g., whether a document is largely cited because it is a milestone in the field or did not find agreement in the scientific landscape). 
Moreover, a method that relies on citations between documents inevitably provide a clearer light on past publications and research trends rather than on more recent ones [49].

\section{Authors Contribution}

Conceptualization, G.E., P.S. and A.C.; methodology, A.C.; formal analysis, A.C.; investigation, A.C.; data curation, A.C. and G.G.; writingoriginal draft preparation, A.C.; writing - review and editing, A.C., A.B., M.L., G.G., P.S., D.D., V.A. and G.E.; visualization, A.C.; supervision, G.E.; funding acquisition, G.E. All authors have read and agreed to the published version of the manuscript.

\section{Funding Information}

This research was supported by grants from the NAP SUG to GE (M4081597, 2015-2021).

\section{Acknowledgements}

We would like to acknowledge An An Lieu (Nanyang Technological University, Singapore) for editing the manuscript.

\section{Conflict of Interest}

The authors declare that the research was conducted in the absence of any commercial or financial relationships that could be construed as a potential conflict of interest.

\section{References}

[1] B. O. Olusanya, A. C. Davis, D. Wertlieb, N.-Y. Boo, M. Nair, R. Halpern, H. Kuper, C. Breinbauer, P. J. De Vries, M. Gladstone, et al., Developmental disabilities among children younger than 5 years in 195 countries and territories, 1990-2016: a systematic analysis for the global burden of disease study 2016, The Lancet Global Health 6 (2018) e1100-e1121. 
[2] N. Scherer, I. Verhey, H. Kuper, Depression and anxiety in parents of children with intellectual and developmental disabilities: A systematic review and meta-analysis, PloS one 14 (2019) e0219888.

[3] G. Solarsh, K. J. Hofman, Developmental disabilities, 2011.

[4] M. Liddle, K. Birkett, A. Bonjour, K. Risma, A collaborative approach to improving health care for children with developmental disabilities, Pediatrics 142 (2018).

[5] P. J. Landrigan, C. B. Schechter, J. M. Lipton, M. C. Fahs, J. Schwartz, Environmental pollutants and disease in american children: estimates of morbidity, mortality, and costs for lead poisoning, asthma, cancer, and developmental disabilities., Environmental health perspectives 110 (2002) 721-728.

[6] P. Mendola, S. G. Selevan, S. Gutter, D. Rice, Environmental factors associated with a spectrum of neurodevelopmental deficits, Mental retardation and developmental disabilities research reviews 8 (2002) 188-197.

[7] P. El-Fishawy, et al., The genetics of autism: key issues, recent findings, and clinical implications, Psychiatric Clinics 33 (2010) 83-105.

[8] E. G. Willcutt, B. F. Pennington, L. Duncan, S. D. Smith, J. M. Keenan, S. Wadsworth, J. C. DeFries, R. K. Olson, Understanding the complex etiologies of developmental disorders: behavioral and molecular genetic approaches, Journal of developmental and behavioral pediatrics: JDBP 31 (2010) 533.

[9] H. C. Mefford, M. L. Batshaw, E. P. Hoffman, Genomics, intellectual disability, and autism, New England Journal of Medicine 366 (2012) 733-743.

[10] B. Kiely, S. Vettam, A. Adesman, Utilization of genetic testing among children with developmental disabilities in the united states, The application of clinical genetics 9 (2016) 93.

[11] A. C. Sousa, From refrigerator mothers to warrior-heroes: The cultural identity transformation of mothers raising children with intellectual disabilities, Symbolic Interaction 34 (2011) 220-243. 
[12] B. Bettelheim, Empty fortress, Simon and Schuster, 1972.

[13] G. Mahoney, A. Powell, Modifying parent-child interaction: Enhancing the development of handicapped children, The Journal of Special Education 22 (1988) 82-96.

[14] L. E. Smith, J. S. Greenberg, M. M. Seltzer, J. Hong, Symptoms and behavior problems of adolescents and adults with autism: Effects of mother-child relationship quality, warmth, and praise, American Journal on Mental Retardation 113 (2008) 387-402.

[15] E. D. Gerstein, K. A. Crnic, Family interactions and developmental risk associated with early cognitive delay: Influences on children's behavioral competence, Journal of Clinical Child \& Adolescent Psychology 47 (2018) S100-S112.

[16] C. O'Toole, A. S.-Y. Lee, F. E. Gibbon, A. K. van Bysterveldt, N. J. Hart, Parent-mediated interventions for promoting communication and language development in young children with down syndrome, Cochrane Database of Systematic Reviews (2018).

[17] N. K. Mackes, D. Golm, S. Sarkar, R. Kumsta, M. Rutter, G. Fairchild, M. A. Mehta, E. J. Sonuga-Barke, et al., Early childhood deprivation is associated with alterations in adult brain structure despite subsequent environmental enrichment, Proceedings of the National Academy of Sciences 117 (2020) 641-649.

[18] A. Bizzego, M. Lim, D. Dimitriou, G. Esposito, The role of the family network when raising a child with a disability in low-and middle-income countries, Disabilities 1 (2021) 58-68.

[19] A. Bizzego, M. Lim, G. Schiavon, G. Esposito, Children with developmental disabilities in low-and middle-income countries: More neglected and physically punished, International Journal of Environmental Research and Public Health 17 (2020) 7009.

[20] A. Bizzego, M. Lim, G. Schiavon, P. Setoh, G. Gabrieli, D. Dimitriou, G. Esposito, Child disability and caregiving in low and middle income countries: Big data approach on open data, Research in Developmental Disabilities 107 (2020) 103795. 
[21] C. Hendricks, J. E. Lansford, K. Deater-Deckard, M. H. Bornstein, Associations between child disabilities and caregiver discipline and violence in low-and middle-income countries, Child development 85 (2014) $513-531$.

[22] L. A. Osborne, P. Reed, The relationship between parenting stress and behavior problems of children with autistic spectrum disorders, Exceptional Children 76 (2009) 54-73.

[23] P. Engle, M. Black, J. Behrman, M. de Mello, P. Gertler, L. Kapiriri, et al., Child development in developing countries 3, Strategies to avoid the loss of developmental potential in more than 200 (2007).

[24] U. Bronfenbrenner, The ecology of human development, Harvard university press, 1979.

[25] J. Henrich, S. J. Heine, A. Norenzayan, Most people are not weird, Nature 466 (2010) 29-29.

[26] E. Gaad, Cross-cultural perspectives on the effect of cultural attitudes towards inclusion for children with intellectual disabilities, International Journal of Inclusive Education 8 (2004) 311-328.

[27] S. Y. Wong, T. K. Wong, I. Martinson, A. C. Lai, W. Chen, Y. He, Needs of chinese parents of children with developmental disability, Journal of Learning Disabilities 8 (2004) 141-158.

[28] B. Zablotsky, L. I. Black, M. J. Maenner, L. A. Schieve, M. L. Danielson, R. H. Bitsko, S. J. Blumberg, M. D. Kogan, C. A. Boyle, Prevalence and trends of developmental disabilities among children in the united states: 2009-2017, Pediatrics 144 (2019) e20190811.

[29] C. A. Boyle, S. Boulet, L. A. Schieve, R. A. Cohen, S. J. Blumberg, M. Yeargin-Allsopp, S. Visser, M. D. Kogan, Trends in the prevalence of developmental disabilities in us children, 1997-2008, Pediatrics 127 (2011) 1034-1042.

[30] A. H. Bittles, E. J. Glasson, Increased longevity and the comorbidities associated with intellectual and developmental disability, Mac Keith Press, 2010. 
[31] A. Coppus, People with intellectual disability: what do we know about adulthood and life expectancy?, Developmental disabilities research reviews 18 (2013) 6-16.

[32] H. J. Williamson, G. M. Contreras, E. S. Rodriguez, J. M. Smith, E. A. Perkins, Health care access for adults with intellectual and developmental disabilities: A scoping review, OTJR: occupation, participation and health 37 (2017) 227-236.

[33] D. Braddock, Aging and developmental disabilities: Demographic and policy issues affecting american families, The best of AAMR: Families and mental retardation: A collection of notable AAMR journal articles across the 20th century (2002) 345-350.

[34] D. Braddock, R. Hemp, M. C. Rizzolo, L. Haffer, E. S. Tanis, J. Wu, The state of the states in developmental disabilities, volume 444, American Association on Intellectual and Developmental Disabilities ..., 2008.

[35] S. L. Parish, Z. E. Lutwick, A critical analysis of the emerging crisis in long-term care for people with developmental disabilities, Social Work 50 (2005) 345-354.

[36] J. D. Southward, K. Kyzar, Predictors of competitive employment for students with intellectual and/or developmental disabilities, Education and Training in Autism and Developmental Disabilities 52 (2017) 2637 .

[37] N.-H. Kim, G. El Hoyek, D. Chau, Long-term care of the aging population with intellectual and developmental disabilities, Clinics in geriatric medicine 27 (2011) 291-300.

[38] C. e. Lee, M. M. Burke, C. R. Stelter, Exploring the perspectives of parents and siblings toward future planning for individuals with intellectual and developmental disabilities, Intellectual and developmental disabilities 57 (2019) 198-211.

[39] L. K. Koegel, J. K. Harrower, R. L. Koegel, Support for children with developmental disabilities in full inclusion classrooms through selfmanagement, Journal of Positive Behavior Interventions 1 (1999) 2634 . 
[40] J. Katz, P. Mirenda, Including students with developmental disabilities in general education classrooms: Educational benefits, International journal of special education 17 (2002) 14-24.

[41] J. W. Johnson, J. McDonnell, V. N. Holzwarth, K. Hunter, The efficacy of embedded instruction for students with developmental disabilities enrolled in general education classes, Journal of Positive Behavior Interventions 6 (2004) 214-227.

[42] D. M. Kagohara, L. van der Meer, S. Ramdoss, M. F. O'Reilly, G. E. Lancioni, T. N. Davis, M. Rispoli, R. Lang, P. B. Marschik, D. Sutherland, et al., Using ipods $\AA$ and ipads $\AA$ in teaching programs for individuals with developmental disabilities: A systematic review, Research in developmental disabilities 34 (2013) 147-156.

[43] J. Hou, X. Yang, C. Chen, Emerging trends and new developments in information science: A document co-citation analysis (2009-2016), Scientometrics 115 (2018) 869-892.

[44] G. Gaggero, A. Bonassi, S. Dellantonio, L. Pastore, V. Aryadoust, G. Esposito, A scientometric review of alexithymia: Mapping thematic and disciplinary shifts in half a century of research, Frontiers in psychiatry 11 (2020) 1405.

[45] H. Wickham, M. H. Wickham, Package 'stringr', 2019.

[46] H. Wickham, The tidyverse, R package ver 1 (2017) 1.

[47] A. South, rworldmap: a new $\mathrm{r}$ package for mapping global data., $\mathrm{R}$ Journal 3 (2011).

[48] E. Neuwirth, M. E. Neuwirth, Package 'RColorBrewer', Technical Report, CRAN 2011-06-17 08: 34: 00. Apache License 2.0, 2011.

[49] A. Carollo, J. P. M. Balagtas, M. J.-Y. Neoh, G. Esposito, A scientometric approach to review the role of the medial preoptic area (mpoa) in parental behavior, Brain Sciences 11 (2021) 393.

[50] V. Aryadoust, H. A. H. Tan, L. Y. Ng, A scientometric review of rasch measurement: The rise and progress of a specialty, Frontiers in psychology 10 (2019) 2197. 
[51] C. Chen, The citespace manual, College of Computing and Informatics; Drexel University: Philadelphia, PA, USA (2014).

[52] C. Chen, F. Ibekwe-SanJuan, J. Hou, The structure and dynamics of cocitation clusters: A multiple-perspective cocitation analysis, Journal of the American Society for information Science and Technology 61 (2010) 1386-1409.

[53] T. S. Kuhn, The structure of scientific revolutions, University of Chicago press, 2012.

[54] E. Simonoff, A. Pickles, T. Charman, S. Chandler, T. Loucas, G. Baird, Psychiatric disorders in children with autism spectrum disorders: prevalence, comorbidity, and associated factors in a population-derived sample, Journal of the American Academy of Child \& Adolescent Psychiatry 47 (2008) 921-929.

[55] A. P. Association, et al., Diagnostic and statistical manual of mental disorders (DSM-5®), American Psychiatric Pub, 2013.

[56] S. Richards, N. Aziz, S. Bale, D. Bick, S. Das, J. Gastier-Foster, W. W. Grody, M. Hegde, E. Lyon, E. Spector, et al., Standards and guidelines for the interpretation of sequence variants: a joint consensus recommendation of the american college of medical genetics and genomics and the association for molecular pathology, Genetics in medicine 17 (2015) 405-423.

[57] M. Lek, K. J. Karczewski, E. V. Minikel, K. E. Samocha, E. Banks, T. Fennell, A. H. O'Donnell-Luria, J. S. Ware, A. J. Hill, B. B. Cummings, et al., Analysis of protein-coding genetic variation in 60,706 humans, Nature 536 (2016) 285-291.

[58] A. Caspi, K. Sugden, T. E. Moffitt, A. Taylor, I. W. Craig, H. Harrington, J. McClay, J. Mill, J. Martin, A. Braithwaite, et al., Influence of life stress on depression: moderation by a polymorphism in the 5-htt gene, Science 301 (2003) 386-389.

[59] A. Caspi, J. McClay, T. E. Moffitt, J. Mill, J. Martin, I. W. Craig, A. Taylor, R. Poulton, Role of genotype in the cycle of violence in maltreated children, Science 297 (2002) 851-854. 
[60] B. L. Baker, J. Blacher, K. A. Crnic, C. Edelbrock, Behavior problems and parenting stress in families of three-year-old children with and without developmental delays, American Journal on Mental Retardation 107 (2002) 433-444.

[61] B. L. Baker, L. McIntyre, J. Blacher, K. Crnic, C. Edelbrock, C. Low, Pre-school children with and without developmental delay: behaviour problems and parenting stress over time, Journal of Intellectual Disability Research 47 (2003) 217-230.

[62] C. R. Marshall, A. Noor, J. B. Vincent, A. C. Lionel, L. Feuk, J. Skaug, M. Shago, R. Moessner, D. Pinto, Y. Ren, et al., Structural variation of chromosomes in autism spectrum disorder, The American Journal of Human Genetics 82 (2008) 477-488.

[63] A. Fraser, C. Macdonald-Wallis, K. Tilling, A. Boyd, J. Golding, G. Davey Smith, J. Henderson, J. Macleod, L. Molloy, A. Ness, et al., Cohort profile: the avon longitudinal study of parents and children: Alspac mothers cohort, International journal of epidemiology 42 (2013) 97-110.

[64] J. Sebat, B. Lakshmi, D. Malhotra, J. Troge, C. Lese-Martin, T. Walsh, B. Yamrom, S. Yoon, A. Krasnitz, J. Kendall, et al., Strong association of de novo copy number mutations with autism, Science 316 (2007) 445-449.

[65] J. Hallmayer, S. Cleveland, A. Torres, J. Phillips, B. Cohen, T. Torigoe, J. Miller, A. Fedele, J. Collins, K. Smith, et al., Genetic heritability and shared environmental factors among twin pairs with autism, Archives of general psychiatry 68 (2011) 1095-1102.

[66] D. Pinto, A. T. Pagnamenta, L. Klei, R. Anney, D. Merico, R. Regan, J. Conroy, T. R. Magalhaes, C. Correia, B. S. Abrahams, et al., Functional impact of global rare copy number variation in autism spectrum disorders, Nature 466 (2010) 368-372.

[67] S. J. Sanders, M. T. Murtha, A. R. Gupta, J. D. Murdoch, M. J. Raubeson, A. J. Willsey, A. G. Ercan-Sencicek, N. M. DiLullo, N. N. Parikshak, J. L. Stein, et al., De novo mutations revealed by wholeexome sequencing are strongly associated with autism, Nature 485 (2012) 237-241. 
[68] N. Risch, D. Spiker, L. Lotspeich, N. Nouri, D. Hinds, J. Hallmayer, L. Kalaydjieva, P. McCague, S. Dimiceli, T. Pitts, et al., A genomic screen of autism: evidence for a multilocus etiology, The American Journal of Human Genetics 65 (1999) 493-507.

[69] S. Chakrabarti, E. Fombonne, Pervasive developmental disorders in preschool children, Jama 285 (2001) 3093-3099.

[70] J. Piven, P. Palmer, D. Jacobi, D. Childress, S. Arndt, Broader autism phenotype: evidence from a family history study of multiple-incidence autism families, American Journal of Psychiatry 154 (1997) 185-190.

[71] L. Zwaigenbaum, S. Bryson, T. Rogers, W. Roberts, J. Brian, P. Szatmari, Behavioral manifestations of autism in the first year of life, International journal of developmental neuroscience 23 (2005) 143-152.

[72] S. Baron-Cohen, J. Allen, C. Gillberg, et al., Can autism be detected at 18 months? the needle, the haystack and the chat, British journal of psychiatry 161 (1992) 839-839.

[73] A. P. A. T. F. on DSM-IV., Dsm-iv sourcebook, volume 1, American Psychiatric Pub, 1994.

[74] K. G. Kramlinger, R. M. Post, Ultra-rapid and ultradian cycling in bipolar affective illness, The British Journal of Psychiatry 168 (1996) 314-323.

[75] P. M. Plotsky, M. J. Meaney, Early, postnatal experience alters hypothalamic corticotropin-releasing factor (crf) mrna, median eminence crf content and stress-induced release in adult rats, Molecular brain research 18 (1993) 195-200.

[76] L. Abbeduto, M. M. Seltzer, P. Shattuck, M. W. Krauss, G. Orsmond, M. M. Murphy, Psychological well-being and coping in mothers of youths with autism, down syndrome, orfragile x syndrome, American Journal on Mental Retardation 109 (2004) 237-254.

[77] A. Rauch, D. Wieczorek, E. Graf, T. Wieland, S. Endele, T. Schwarzmayr, B. Albrecht, D. Bartholdi, J. Beygo, N. Di Donato, et al., Range 
of genetic mutations associated with severe non-syndromic sporadic intellectual disability: an exome sequencing study, The Lancet 380 (2012) 1674-1682.

[78] E. Fombonne, The epidemiology of autism: a review, Psychological medicine 29 (1999) 769-786.

[79] F. P. Glascoe, Parents' concerns about children's development: prescreening technique or screening test?, Pediatrics 99 (1997) 522-528.

[80] B. J. O’Roak, L. Vives, S. Girirajan, E. Karakoc, N. Krumm, B. P. Coe, R. Levy, A. Ko, C. Lee, J. D. Smith, et al., Sporadic autism exomes reveal a highly interconnected protein network of de novo mutations, Nature 485 (2012) 246-250.

[81] H. Li, R. Durbin, Fast and accurate short read alignment with burrowswheeler transform, bioinformatics 25 (2009) 1754-1760.

[82] L. Lefebvre, S. Viville, S. C. Barton, F. Ishino, E. B. Keverne, M. A. Surani, Abnormal maternal behaviour and growth retardation associated with loss of the imprinted gene mest, Nature genetics 20 (1998) 163-169.

[83] M. Auranen, R. Vanhala, T. Varilo, K. Ayers, E. Kempas, T. Ylisaukko-oja, J. S. Sinsheimer, L. Peltonen, I. Järvelä, A genomewide screen for autism-spectrum disorders: evidence for a major susceptibility locus on chromosome 3q25-27, The American Journal of Human Genetics 71 (2002) 777-790.

[84] J. Baio, L. Wiggins, D. L. Christensen, M. J. Maenner, J. Daniels, Z. Warren, M. Kurzius-Spencer, W. Zahorodny, C. R. Rosenberg, T. White, et al., Prevalence of autism spectrum disorder among children aged 8 years - autism and developmental disabilities monitoring network, 11 sites, united states, 2014, MMWR Surveillance Summaries 67 (2018) 1.

[85] E. Fombonne, Epidemiological surveys of autism and other pervasive developmental disorders: an update, Journal of autism and developmental disorders 33 (2003) 365-382. 
[86] N. Sand, M. Silverstein, F. P. Glascoe, V. B. Gupta, T. P. Tonniges, K. G. O'Connor, Pediatricians' reported practices regarding developmental screening: do guidelines work? do they help?, Pediatrics 116 (2005) 174-179.

[87] I. A. Adzhubei, S. Schmidt, L. Peshkin, V. E. Ramensky, A. Gerasimova, P. Bork, A. S. Kondrashov, S. R. Sunyaev, A method and server for predicting damaging missense mutations, Nature methods 7 (2010) 248-249.

[88] G. Baird, T. Charman, S. Baron-Cohen, A. Cox, J. Swettenham, S. Wheelwright, A. Drew, A screening instrument for autism at 18 months of age: a 6-year follow-up study, Journal of the American Academy of Child \& Adolescent Psychiatry 39 (2000) 694-702.

[89] J. Osterling, G. Dawson, Early recognition of children with autism: A study of first birthday home videotapes, Journal of autism and developmental disorders 24 (1994) 247-257.

[90] M. Rutter, T. E. Moffitt, A. Caspi, Gene-environment interplay and psychopathology: Multiple varieties but real effects, Journal of child Psychology and Psychiatry 47 (2006) 226-261.

[91] G. Dawson, Early behavioral intervention, brain plasticity, and the prevention of autism spectrum disorder, Development and psychopathology 20 (2008) 775-803.

[92] A. Trouton, F. M. Spinath, R. Plomin, Twins early development study (teds): a multivariate, longitudinal genetic investigation of language, cognition and behavior problems in childhood, Twin Research and Human Genetics 5 (2002) 444-448.

[93] S. Ozonoff, G. S. Young, A. Carter, D. Messinger, N. Yirmiya, L. Zwaigenbaum, S. Bryson, L. J. Carver, J. N. Constantino, K. Dobkins, et al., Recurrence risk for autism spectrum disorders: a baby siblings research consortium study, Pediatrics 128 (2011) e488e495.

[94] E. Fombonne, Epidemiology of pervasive developmental disorders, Pediatric research 65 (2009) 591-598. 
[95] A. Estes, J. Munson, G. Dawson, E. Koehler, X.-H. Zhou, R. Abbott, Parenting stress and psychological functioning among mothers of preschool children with autism and developmental delay, Autism 13 (2009) 375-387.

[96] S. A. Hayes, S. L. Watson, The impact of parenting stress: A metaanalysis of studies comparing the experience of parenting stress in parents of children with and without autism spectrum disorder, Journal of autism and developmental disorders 43 (2013) 629-642.

[97] G. Dawson, S. Rogers, J. Munson, M. Smith, J. Winter, J. Greenson, A. Donaldson, J. Varley, Randomized, controlled trial of an intervention for toddlers with autism: the early start denver model, Pediatrics 125 (2010) e17-e23.

[98] H. Smedje, J.-E. Broman, J. Hetta, A.-L. Von Knorring, Psychometric properties of a swedish version of the "strengths and difficulties questionnaire", European child \& adolescent psychiatry 8 (1999) 63-70.

[99] C. P. Johnson, S. M. Myers, et al., Identification and evaluation of children with autism spectrum disorders, Pediatrics 120 (2007) 11831215 .

[100] M. Nielsen, D. Haun, J. Kärtner, C. H. Legare, The persistent sampling bias in developmental psychology: A call to action, Journal of Experimental Child Psychology 162 (2017) 31-38.

[101] S. Bundey, H. Alam, A five-year prospective study of the health of children in different ethnic groups, with particular reference to the effect of inbreeding, European Journal of Human Genetics 1 (1993) 206-219.

[102] M. Durkin, The epidemiology of developmental disabilities in lowincome countries, Mental retardation and developmental disabilities research reviews 8 (2002) 206-211.

[103] M.-T. A. Obama, L. Dongmo, C. Nkemayim, J. Mbede, P. Hagbe, Stroke in children in yaounde, cameroon, Indian pediatrics 31 (1994) 791-791. 
[104] Y. Balarajan, U. Ramakrishnan, E. Özaltin, A. H. Shankar, S. Subramanian, Anaemia in low-income and middle-income countries, The lancet 378 (2011) 2123-2135.

[105] S. E. Lee, S. A. Talegawkar, M. Merialdi, L. E. Caulfield, Dietary intakes of women during pregnancy in low-and middle-income countries, Public health nutrition 16 (2013) 1340-1353.

[106] R. E. Black, C. G. Victora, S. P. Walker, Z. A. Bhutta, P. Christian, M. De Onis, M. Ezzati, S. Grantham-McGregor, J. Katz, R. Martorell, et al., Maternal and child undernutrition and overweight in low-income and middle-income countries, The lancet 382 (2013) 427-451.

[107] J. R. West, C. R. Goodlett, Teratogenic effects of alcohol on brain development, Annals of medicine 22 (1990) 319-325.

[108] J. Hutchings, J. Potterton, Developmental delay in hiv-exposed infants in harare, zimbabwe, Vulnerable Children and Youth Studies 9 (2014) $43-55$.

[109] V. P. Verghese, L. Hendson, A. Singh, T. Guenette, J. Gratrix, J. L. Robinson, Early childhood neurodevelopmental outcomes in infants exposed to infectious syphilis in utero, The Pediatric infectious disease journal 37 (2018) 576-579.

[110] D. L. Cameron, S. Nixon, P. Parnes, M. Pidsadny, Children with disabilities in low-income countries, Paediatrics \& child health 10 (2005) 269-272.

[111] J. B. Babigumira, I. Morgan, A. Levin, Health economics of rubella: a systematic review to assess the value of rubella vaccination, BMC Public Health 13 (2013) 1-12.

[112] E. Gordon-Lipkin, A. Hoon, C. A. Pardo, Prenatal cytomegalovirus, rubella, and zika virus infections associated with developmental disabilities: past, present, and future, Developmental Medicine \& Child Neurology 63 (2021) 135-143.

[113] S. Islam, M. S. Durkin, S. S. Zaman, Socioeconomic status and the prevalence of mental retardation in bangladesh, Mental Retardation 31 (1993) 412. 
[114] E. Emerson, Poverty and people with intellectual disabilities, Mental retardation and developmental disabilities research reviews 13 (2007) 107-113.

[115] J. H. Beitchman, D. P. Cantwell, S. R. Forness, K. A. Kavale, J. M. Kauffman, et al., Practice parameters for the assessment and treatment of children and adolescents with language and learning disorders, Journal of the American Academy of Child \& Adolescent Psychiatry 37 (1998) 46S-62S.

[116] P. Howlin, L. Mawhood, M. Rutter, Autism and developmental receptive language disorder - a follow-up comparison in early adult life. ii: Social, behavioural, and psychiatric outcomes, Journal of Child Psychology and Psychiatry 41 (2000) 561-578.

[117] J. B. Tomblin, N. L. Records, X. Zhang, A system for the diagnosis of specific language impairment in kindergarten children, Journal of Speech, Language, and Hearing Research 39 (1996) 1284-1294.

[118] H. W. Catts, The relationship between speech-language impairments and reading disabilities, Journal of Speech, Language, and Hearing Research 36 (1993) 948-958.

[119] J. H. Beitchman, J. Hood, A. Inglis, Psychiatric risk in children with speech and language disorders, Journal of Abnormal Child Psychology 18 (1990) 283-296.

[120] J. H. Beitchman, E. Brownlie, A. Inglis, J. Wild, R. Mathews, D. Schachter, R. Kroll, S. Martin, B. Ferguson, W. Lancee, Sevenyear follow-up of speech/language-impaired and control children: Speech/language stability and outcome, Journal of the American Academy of Child \& Adolescent Psychiatry 33 (1994) 1322-1330.

[121] J. H. Beitchman, B. Wilson, E. Brownlie, H. Walters, A. Inglis, W. Lancee, Long-term consistency in speech/language profiles: Ii. behavioral, emotional, and social outcomes, Journal of the American Academy of Child \& Adolescent Psychiatry 35 (1996) 815-825.

[122] N. J. Cohen, R. Menna, D. D. Vallance, M. A. Barwick, N. Im, N. B. Horodezky, Language, social cognitive processing, and behavioral char- 
acteristics of psychiatrically disturbed children with previously identified and unsuspected language impairments, Journal of Child Psychology and Psychiatry 39 (1998) 853-864.

[123] P. S. Dale, C. Crain-Thoreson, A. Notari-Syverson, K. Cole, Parentchild book reading as an intervention technique for young children with language delays, Topics in Early Childhood Special Education 16 (1996) 213-235.

[124] M. L. Hemmeter, A. P. Kaiser, Enhanced milieu teaching: Effects of parent-implemented language intervention, Journal of Early Intervention 18 (1994) 269-289.

[125] L. Girolametto, P. S. Pearce, E. Weitzman, Interactive focused stimulation for toddlers with expressive vocabulary delays, Journal of Speech, Language, and Hearing Research 39 (1996) 1274-1283.

[126] R. L. Koegel, L. Schreibman, L. M. Loos, H. Dirlich-Wilhelm, G. Dunlap, F. R. Robbins, A. J. Plienis, Consistent stress profiles in mothers of children with autism, Journal of autism and developmental disorders 22 (1992) 205-216.

[127] J. Elander, M. Rutter, Use and development of the rutter parents' and teachers' scales., International Journal of Methods in Psychiatric Research (1996).

[128] R. Goodman, The strengths and difficulties questionnaire: a research note, Journal of child psychology and psychiatry 38 (1997) 581-586.

[129] T. M. Achenbach, L. A. Rescorla, Manual for the ASEBA preschool forms and profiles, volume 30, Burlington, VT: University of Vermont, Research center for children, youth ..., 2000.

[130] S. J. Sanders, A. G. Ercan-Sencicek, V. Hus, R. Luo, M. T. Murtha, D. Moreno-De-Luca, S. H. Chu, M. P. Moreau, A. R. Gupta, S. A. Thomson, et al., Multiple recurrent de novo cnvs, including duplications of the 7q11. 23 williams syndrome region, are strongly associated with autism, Neuron 70 (2011) 863-885. 
[131] A. Bremer, M. Giacobini, M. Eriksson, P. Gustavsson, V. Nordin, E. Fernell, C. Gillberg, A. Nordgren, A. Uppströmer, B.-M. Anderlid, et al., Copy number variation characteristics in subpopulations of patients with autism spectrum disorders, American Journal of Medical Genetics Part B: Neuropsychiatric Genetics 156 (2011) 115-124.

[132] C. Babbs, D. Lloyd, A. T. Pagnamenta, S. R. Twigg, J. Green, S. J. McGowan, G. Mirza, R. Naples, V. P. Sharma, E. V. Volpi, et al., De novo and rare inherited mutations implicate the transcriptional coregulator tcf20/spbp in autism spectrum disorder, Journal of medical genetics 51 (2014) 737-747.

[133] M. D. Kogan, S. J. Blumberg, L. A. Schieve, C. A. Boyle, J. M. Perrin, R. M. Ghandour, G. K. Singh, B. B. Strickland, E. Trevathan, P. C. van Dyck, Prevalence of parent-reported diagnosis of autism spectrum disorder among children in the us, 2007, Pediatrics 124 (2009) 13951403.

[134] M. Yeargin-Allsopp, C. Rice, T. Karapurkar, N. Doernberg, C. Boyle, C. Murphy, Prevalence of autism in a us metropolitan area, Jama 289 (2003) 49-55.

[135] J. N. Constantino, R. D. Todd, Autistic traits in the general population: a twin study, Archives of general psychiatry 60 (2003) 524-530.

[136] G. Polanczyk, M. S. De Lima, B. L. Horta, J. Biederman, L. A. Rohde, The worldwide prevalence of adhd: a systematic review and metaregression analysis, American journal of psychiatry 164 (2007) 942-948.

[137] N. Bayley, Bayley scales of infant and toddler development, PsychCorp, Pearson, 2006.

[138] J. L. Matson, M. Shoemaker, Intellectual disability and its relationship to autism spectrum disorders, Research in developmental disabilities 30 (2009) 1107-1114.

[139] L. A. Osborne, L. McHugh, J. Saunders, P. Reed, Parenting stress reduces the effectiveness of early teaching interventions for autistic spectrum disorders, Journal of autism and developmental disorders 38 (2008) 1092. 
[140] K. Whittingham, K. Sofronoff, J. Sheffield, M. R. Sanders, Stepping stones triple p: An rct of a parenting program with parents of a child diagnosed with an autism spectrum disorder, Journal of abnormal child psychology 37 (2009) 469.

[141] J. Halvardson, J. J. Zhao, A. Zaghlool, C. Wentzel, P. GeorgiiHemming, E. Månsson, H. E. Sävmarker, G. Brandberg, C. S. Zander, A.-C. Thuresson, et al., Mutations in hecw2 are associated with intellectual disability and epilepsy, Journal of medical genetics 53 (2016) 697-704.

[142] F. F. Hamdan, C. T. Myers, P. Cossette, P. Lemay, D. Spiegelman, A. D. Laporte, C. Nassif, O. Diallo, J. Monlong, M. Cadieux-Dion, et al., High rate of recurrent de novo mutations in developmental and epileptic encephalopathies, The American Journal of Human Genetics 101 (2017) 664-685.

[143] D. T. Miller, M. P. Adam, S. Aradhya, L. G. Biesecker, A. R. Brothman, N. P. Carter, D. M. Church, J. A. Crolla, E. E. Eichler, C. J. Epstein, et al., Consensus statement: chromosomal microarray is a first-tier clinical diagnostic test for individuals with developmental disabilities or congenital anomalies, The American Journal of Human Genetics 86 (2010) 749-764.

[144] J. De Ligt, M. H. Willemsen, B. W. Van Bon, T. Kleefstra, H. G. Yntema, T. Kroes, A. T. Vulto-van Silfhout, D. A. Koolen, P. De Vries, C. Gilissen, et al., Diagnostic exome sequencing in persons with severe intellectual disability, New England Journal of Medicine 367 (2012) 1921-1929.

[145] Y. Yang, D. M. Muzny, J. G. Reid, M. N. Bainbridge, A. Willis, P. A. Ward, A. Braxton, J. Beuten, F. Xia, Z. Niu, et al., Clinical wholeexome sequencing for the diagnosis of mendelian disorders, New England Journal of Medicine 369 (2013) 1502-1511.

[146] Y. Yang, D. M. Muzny, F. Xia, Z. Niu, R. Person, Y. Ding, P. Ward, A. Braxton, M. Wang, C. Buhay, et al., Molecular findings among patients referred for clinical whole-exome sequencing, Jama 312 (2014) $1870-1879$. 
[147] J. B. Moeschler, M. Shevell, et al., Comprehensive evaluation of the child with intellectual disability or global developmental delays, Pediatrics 134 (2014) e903-e918.

[148] K. M. Bowling, M. L. Thompson, M. D. Amaral, C. R. Finnila, S. M. Hiatt, K. L. Engel, J. N. Cochran, K. B. Brothers, K. M. East, D. E. Gray, et al., Genomic diagnosis for children with intellectual disability and/or developmental delay, Genome medicine 9 (2017) 1-11.

[149] S. Reilly, B. Tomblin, J. Law, C. McKean, F. K. Mensah, A. Morgan, S. Goldfeld, J. M. Nicholson, M. Wake, Specific language impairment: a convenient label for whom?, International Journal of Language \& Communication Disorders 49 (2014) 416-451.

[150] M. Elsabbagh, G. Divan, Y.-J. Koh, Y. S. Kim, S. Kauchali, C. Marcín, C. Montiel-Nava, V. Patel, C. S. Paula, C. Wang, et al., Global prevalence of autism and other pervasive developmental disorders, Autism research 5 (2012) 160-179.

[151] B. Zablotsky, L. I. Black, M. J. Maenner, L. A. Schieve, S. J. Blumberg, Estimated prevalence of autism and other developmental disabilities following questionnaire changes in the 2014 national health interview survey, 2015.

[152] Y. S. Kim, B. L. Leventhal, Y.-J. Koh, E. Fombonne, E. Laska, E.-C. Lim, K.-A. Cheon, S.-J. Kim, Y.-K. Kim, H. Lee, et al., Prevalence of autism spectrum disorders in a total population sample, American Journal of Psychiatry 168 (2011) 904-912.

[153] B. R. Vohr, L. L. Wright, A. M. Dusick, L. Mele, J. Verter, J. J. Steichen, N. P. Simon, D. C. Wilson, S. Broyles, C. R. Bauer, et al., Neurodevelopmental and functional outcomes of extremely low birth weight infants in the national institute of child health and human development neonatal research network, 1993-1994, Pediatrics 105 (2000) $1216-1226$.

[154] S. Saigal, L. A. Hoult, D. L. Streiner, B. L. Stoskopf, P. L. Rosenbaum, School difficulties at adolescence in a regional cohort of children who were extremely low birth weight, Pediatrics 105 (2000) 325-331. 
[155] S. Saigal, L. den Ouden, D. Wolke, L. Hoult, N. Paneth, D. L. Streiner, A. Whitaker, J. Pinto-Martin, School-age outcomes in children who were extremely low birth weight from four international populationbased cohorts, Pediatrics 112 (2003) 943-950.

[156] L. Luoma, E. H. MD, A. M. MD, T. A. PhD, Speech and language development of children born at 32 weeks' gestation: a 5-year prospective follow-up study, Developmental Medicine \& Child Neurology 40 (1998) 380-387.

[157] A. Stewart, L. Rifkin, P. Amess, V. Kirkbride, J. Townsend, D. Miller, S. Lewis, D. Kingsley, I. Moseley, O. Foster, et al., Brain structure and neurocognitive and behavioural function in adolescents who were born very preterm, The lancet 353 (1999) 1653-1657.

[158] N. S. Wood, N. Marlow, K. Costeloe, A. T. Gibson, A. R. Wilkinson, Neurologic and developmental disability after extremely preterm birth, New England Journal of Medicine 343 (2000) 378-384.

[159] N. Marlow, Neurocognitive outcome after very preterm birth, Archives of Disease in Childhood-Fetal and Neonatal Edition 89 (2004) F224F228.

[160] N. Marlow, D. Wolke, M. A. Bracewell, M. Samara, Neurologic and developmental disability at six years of age after extremely preterm birth, New England Journal of Medicine 352 (2005) 9-19.

[161] L. Mercer, S. Creighton, J. Holden, M. Lewis, Parental perspectives on the causes of an autism spectrum disorder in their children, Journal of Genetic Counseling 15 (2006) 41-50.

[162] A. J. Wakefield, S. H. Murch, A. Anthony, J. Linnell, D. M. Casson, M. Malik, M. Berelowitz, A. P. Dhillon, M. A. Thomson, P. Harvey, et al., Retracted: Ileal-lymphoid-nodular hyperplasia, non-specific colitis, and pervasive developmental disorder in children, 1998.

[163] B. Taylor, E. Miller, C. Farrington, M.-C. Petropoulos, I. FavotMayaud, J. Li, P. A. Waight, Autism and measles, mumps, and rubella vaccine: no epidemiological evidence for a causal association, The Lancet 353 (1999) 2026-2029. 
[164] E. Fombonne, S. Chakrabarti, No evidence for a new variant of measlesmumps-rubella-induced autism, Pediatrics 108 (2001) e58-e58.

[165] J. A. Kaye, M. del Mar Melero-Montes, H. Jick, Mumps, measles, and rubella vaccine and the incidence of autism recorded by general practitioners: a time trend analysis, Bmj 322 (2001) 460-463.

[166] P. Bolton, H. Macdonald, A. Pickles, P. Rios, S. Goode, M. Crowson, A. Bailey, M. Rutter, A case-control family history study of autism, Journal of child Psychology and Psychiatry 35 (1994) 877-900.

[167] R. Muhle, S. V. Trentacoste, I. Rapin, The genetics of autism, Pediatrics 113 (2004) e472-e486.

[168] B. S. Abrahams, D. H. Geschwind, Advances in autism genetics: on the threshold of a new neurobiology, Nature reviews genetics 9 (2008) 341-355.

[169] J. T. Glessner, K. Wang, G. Cai, O. Korvatska, C. E. Kim, S. Wood, H. Zhang, A. Estes, C. W. Brune, J. P. Bradfield, et al., Autism genome-wide copy number variation reveals ubiquitin and neuronal genes, Nature 459 (2009) 569-573.

[170] L. A. Weiss, Y. Shen, J. M. Korn, D. E. Arking, D. T. Miller, R. Fossdal, E. Saemundsen, H. Stefansson, M. A. Ferreira, T. Green, et al., Association between microdeletion and microduplication at 16p11. 2 and autism, New England Journal of Medicine 358 (2008) 667-675.

[171] H. C. Mefford, A. J. Sharp, C. Baker, A. Itsara, Z. Jiang, K. Buysse, S. Huang, V. K. Maloney, J. A. Crolla, D. Baralle, et al., Recurrent rearrangements of chromosome 1q21. 1 and variable pediatric phenotypes, New England Journal of Medicine 359 (2008) 1685-1699.

[172] D. T. Miller, Y. Shen, L. A. Weiss, J. Korn, I. Anselm, C. Bridgemohan, G. F. Cox, H. Dickinson, J. Gentile, D. J. Harris, et al., Microdeletion/duplication at 15q13. 2q13. 3 among individuals with features of autism and other neuropsychiatric disorders, Journal of medical genetics 46 (2009) 242-248.

[173] M. A. Eriksson, J. Westerlund, B. M. Anderlid, C. Gillberg, E. Fernell, First-degree relatives of young children with autism spectrum disorders: 
some gender aspects, Research in Developmental Disabilities 33 (2012) 1642-1648.

[174] W. De la Marche, I. Noens, J. Luts, E. Scholte, S. Van Huffel, J. Steyaert, Quantitative autism traits in first degree relatives: evidence for the broader autism phenotype in fathers, but not in mothers and siblings, Autism 16 (2012) 247-260.

[175] D. G. Bosch, F. N. Boonstra, N. de Leeuw, R. Pfundt, W. M. Nillesen, J. de Ligt, C. Gilissen, S. Jhangiani, J. R. Lupski, F. P. Cremers, et al., Novel genetic causes for cerebral visual impairment, European Journal of Human Genetics 24 (2016) 660-665.

[176] A. Tzschach, U. Grasshoff, S. Beck-Woedl, C. Dufke, C. Bauer, M. Kehrer, C. Evers, U. Moog, B. Oehl-Jaschkowitz, N. Di Donato, et al., Next-generation sequencing in x-linked intellectual disability, European Journal of Human Genetics 23 (2015) 1513-1518.

[177] V. A. Cuddapah, R. B. Pillai, K. V. Shekar, J. B. Lane, K. J. Motil, S. A. Skinner, D. C. Tarquinio, D. G. Glaze, G. McGwin, W. E. Kaufmann, et al., Methyl-cpg-binding protein 2 (mecp2) mutation type is associated with disease severity in rett syndrome, Journal of medical genetics 51 (2014) 152-158.

[178] C. Betancur, Etiological heterogeneity in autism spectrum disorders: more than 100 genetic and genomic disorders and still counting, Brain research 1380 (2011) 42-77.

[179] B. J. O'Roak, P. Deriziotis, C. Lee, L. Vives, J. J. Schwartz, S. Girirajan, E. Karakoc, A. P. MacKenzie, S. B. Ng, C. Baker, et al., Exome sequencing in sporadic autism spectrum disorders identifies severe de novo mutations, Nature genetics 43 (2011) 585.

[180] B. M. Neale, Y. Kou, L. Liu, A. Ma'Ayan, K. E. Samocha, A. Sabo, C.-F. Lin, C. Stevens, L.-S. Wang, V. Makarov, et al., Patterns and rates of exonic de novo mutations in autism spectrum disorders, Nature 485 (2012) 242-245.

[181] I. Iossifov, B. J. O'roak, S. J. Sanders, M. Ronemus, N. Krumm, D. Levy, H. A. Stessman, K. T. Witherspoon, L. Vives, K. E. Pat- 
terson, et al., The contribution of de novo coding mutations to autism spectrum disorder, Nature 515 (2014) 216-221.

[182] D. Levy, M. Ronemus, B. Yamrom, Y.-h. Lee, A. Leotta, J. Kendall, S. Marks, B. Lakshmi, D. Pai, K. Ye, et al., Rare de novo and transmitted copy-number variation in autistic spectrum disorders, Neuron 70 (2011) 886-897.

[183] D. Pinto, E. Delaby, D. Merico, M. Barbosa, A. Merikangas, L. Klei, B. Thiruvahindrapuram, X. Xu, R. Ziman, Z. Wang, et al., Convergence of genes and cellular pathways dysregulated in autism spectrum disorders, The American Journal of Human Genetics 94 (2014) 677694.

[184] C. Nava, B. Keren, C. Mignot, A. Rastetter, S. Chantot-Bastaraud, A. Faudet, E. Fonteneau, C. Amiet, C. Laurent, A. Jacquette, et al., Prospective diagnostic analysis of copy number variants using snp microarrays in individuals with autism spectrum disorders, European Journal of Human Genetics 22 (2014) 71-78.

[185] T. Insel, B. Cuthbert, M. Garvey, R. Heinssen, D. S. Pine, K. Quinn, C. Sanislow, P. Wang, Research domain criteria (rdoc): toward a new classification framework for research on mental disorders, 2010.

[186] R. Acuna-Hidalgo, J. A. Veltman, A. Hoischen, New insights into the generation and role of de novo mutations in health and disease, Genome biology 17 (2016) 1-19.

[187] A. S. Allen, S. F. Berkovic, P. Cossette, N. Delanty, D. Dlugos, E. E. Eichler, M. P. Epstein, T. Glauser, D. B. Goldstein, Y. Han, et al., De novo mutations in epileptic encephalopathies, Nature 501 (2013) $217-221$.

[188] S. Girirajan, J. A. Rosenfeld, B. P. Coe, S. Parikh, N. Friedman, A. Goldstein, R. A. Filipink, J. S. McConnell, B. Angle, W. S. Meschino, et al., Phenotypic heterogeneity of genomic disorders and rare copy-number variants, New England Journal of Medicine 367 (2012) 1321-1331.

[189] G. M. Cooper, B. P. Coe, S. Girirajan, J. A. Rosenfeld, T. H. Vu, C. Baker, C. Williams, H. Stalker, R. Hamid, V. Hannig, et al., A 
copy number variation morbidity map of developmental delay, Nature genetics 43 (2011) 838-846.

[190] P. Kumar, S. Henikoff, P. C. Ng, Predicting the effects of coding non-synonymous variants on protein function using the sift algorithm, Nature protocols 4 (2009) 1073.

[191] B. Popp, A. B. Ekici, C. T. Thiel, J. Hoyer, A. Wiesener, C. Kraus, A. Reis, C. Zweier, Exome pool-seq in neurodevelopmental disorders, European Journal of Human Genetics 25 (2017) 1364-1376.

[192] C. F. Wright, T. W. Fitzgerald, W. D. Jones, S. Clayton, J. F. McRae, M. Van Kogelenberg, D. A. King, K. Ambridge, D. M. Barrett, T. Bayzetinova, et al., Genetic diagnosis of developmental disorders in the ddd study: a scalable analysis of genome-wide research data, The Lancet 385 (2015) 1305-1314.

[193] J. Belsky, M. Pluess, Beyond diathesis stress: differential susceptibility to environmental influences., Psychological bulletin 135 (2009) 885.

[194] C. Nosarti, A. Reichenberg, R. M. Murray, S. Cnattingius, M. P. Lambe, L. Yin, J. MacCabe, L. Rifkin, C. M. Hultman, Preterm birth and psychiatric disorders in young adult life, Archives of general psychiatry 69 (2012) 610-617.

[195] M. Begemann, F. I. Rezwan, J. Beygo, L. E. Docherty, J. Kolarova, C. Schroeder, K. Buiting, K. Chokkalingam, F. Degenhardt, E. L. Wakeling, et al., Maternal variants in nlrp and other maternal effect proteins are associated with multilocus imprinting disturbance in offspring, Journal of medical genetics 55 (2018) 497-504.

[196] M. Janecka, S. N. Hansen, A. Modabbernia, H. A. Browne, J. D. Buxbaum, D. E. Schendel, A. Reichenberg, E. T. Parner, D. E. Grice, Parental age and differential estimates of risk for neuropsychiatric disorders: Findings from the danish birth cohort, Journal of the American Academy of Child \& Adolescent Psychiatry 58 (2019) 618-627.

[197] M. Lahey, J. Edwards, Specific language impairment: Preliminary investigation of factors associated with family history and with patterns of language performance, Journal of Speech, Language, and Hearing Research 38 (1995) 643-657. 
[198] P. Tallal, R. Ross, S. Curtiss, Familial aggregation in specific language impairment, journal of Speech and Hearing Disorders 54 (1989) 167173.

[199] D. V. Bishop, T. North, C. Donlan, Genetic basis of specific language impairment: Evidence from a twin study, Developmental Medicine \& Child Neurology 37 (1995) 56-71.

[200] J. B. Tomblin, Familial concentration of developmental language impairment, Journal of Speech and Hearing Disorders 54 (1989) 287-295.

[201] B. A. Lewis, L. A. Thompson, A study of developmental speech and language disorders in twins, Journal of Speech, Language, and Hearing Research 35 (1992) 1086-1094.

[202] B. F. Pennington, J. W. Gilger, D. Pauls, S. A. Smith, S. D. Smith, J. C. DeFries, Evidence for major gene transmission of developmental dyslexia, Jama 266 (1991) 1527-1534.

[203] A. Bailey, A. Le Couteur, I. Gottesman, P. Bolton, E. Simonoff, E. Yuzda, M. Rutter, Autism as a strongly genetic disorder: evidence from a british twin study, Psychological medicine 25 (1995) 63-77.

[204] D. M. Fergusson, L. J. Woodward, L. J. Horwood, Maternal smoking during pregnancy and psychiatric adjustment in late adolescence, Archives of general psychiatry 55 (1998) 721-727.

[205] S. Ward, The predictive validity and accuracy of a screening test for language delay and auditory perceptual disorder, European Journal of Disorders of Communication 27 (1992) 55-72.

[206] A. Bailey, W. Phillips, M. Rutter, Autism: towards an integration of clinical, genetic, neuropsychological, and neurobiological perspectives, Journal of child psychology and psychiatry 37 (1996) 89-126.

[207] J. Law, J. Boyle, F. Harris, A. Harkness, C. Nye, Screening for speech and language delay: a systematic review of the literature, Database of Abstracts of Reviews of Effects (DARE): Quality-assessed Reviews [Internet] (1998). 
[208] G. J. Whitehurst, J. E. Fischel, Practitioner review: Early developmental language delay: What. if anything. should the clinician do about it?, Journal of Child Psychology and Psychiatry 35 (1994) 613-648.

[209] D. P. Cantwell, Attention deficit disorder: a review of the past 10 years, Journal of the American Academy of Child \& Adolescent Psychiatry 35 (1996) 978-987.

[210] T. C. Eley, K. Sugden, A. Corsico, A. M. Gregory, P. Sham, P. McGuffin, R. Plomin, I. W. Craig, Gene-environment interaction analysis of serotonin system markers with adolescent depression, Molecular psychiatry 9 (2004) 908-915.

[211] J. Kaufman, B.-Z. Yang, H. Douglas-Palumberi, S. Houshyar, D. Lipschitz, J. H. Krystal, J. Gelernter, Social supports and serotonin transporter gene moderate depression in maltreated children, Proceedings of the National Academy of Sciences 101 (2004) 17316-17321.

[212] N. A. Fox, K. E. Nichols, H. A. Henderson, K. Rubin, L. Schmidt, D. Hamer, M. Ernst, D. S. Pine, Evidence for a gene-environment interaction in predicting behavioral inhibition in middle childhood, Psychological Science 16 (2005) 921-926.

[213] B. F. Pennington, L. M. McGrath, J. Rosenberg, H. Barnard, S. D. Smith, E. G. Willcutt, A. Friend, J. C. DeFries, R. K. Olson, Gene $\times$ environment interactions in reading disability and attentiondeficit/hyperactivity disorder., Developmental psychology 45 (2009) 77 .

[214] J. Nigg, M. Nikolas, S. A. Burt, Measured gene-by-environment interaction in relation to attention-deficit/hyperactivity disorder, Journal of the American Academy of Child \& Adolescent Psychiatry 49 (2010) 863-873.

[215] T. E. Moffitt, A. Caspi, M. Rutter, Strategy for investigating interactions between measured genes and measured environments, Archives of general psychiatry 62 (2005) 473-481.

[216] J. N. Constantino, Y. Zhang, T. Frazier, A. M. Abbacchi, P. Law, Sibling recurrence and the genetic epidemiology of autism, American Journal of Psychiatry 167 (2010) 1349-1356. 
[217] R. M. Cantor, Molecular genetics of autism, Current Psychiatry Reports 11 (2009) 137-142.

[218] I. R. Gizer, C. Ficks, I. D. Waldman, Candidate gene studies of adhd: a meta-analytic review, Human genetics 126 (2009) 51-90.

[219] J. Cairney, D. Rigoli, J. Piek, Developmental coordination disorder and internalizing problems in children: the environmental stress hypothesis elaborated, Developmental Review 33 (2013) 224-238.

[220] Y. Leitner, The co-occurrence of autism and attention deficit hyperactivity disorder in children-what do we know?, Frontiers in human neuroscience 8 (2014) 268.

[221] A. R. Martin, M. J. Daly, E. B. Robinson, S. E. Hyman, B. M. Neale, Predicting polygenic risk of psychiatric disorders, Biological psychiatry 86 (2019) 97-109.

[222] J. G. Zwicker, S. Harris, A. Klassen, Quality of life domains affected in children with developmental coordination disorder: a systematic review, Child: care, health and development 39 (2013) 562-580.

[223] P. F. Whiting, R. F. Wolff, S. Deshpande, M. Di Nisio, S. Duffy, A. V. Hernandez, J. C. Keurentjes, S. Lang, K. Misso, S. Ryder, et al., Cannabinoids for medical use: a systematic review and meta-analysis, Jama 313 (2015) 2456-2473.

[224] J. A. Bennett, T. Germani, A. M. Haqq, L. Zwaigenbaum, Autism spectrum disorder in prader-willi syndrome: a systematic review, American Journal of Medical Genetics Part A 167 (2015) 2936-2944.

[225] K. McKenzie, M. Milton, G. Smith, H. Ouellette-Kuntz, Systematic review of the prevalence and incidence of intellectual disabilities: current trends and issues, Current Developmental Disorders Reports 3 (2016) 104-115.

[226] V. Anttila, B. Bulik-Sullivan, H. K. Finucane, R. K. Walters, J. Bras, L. Duncan, V. Escott-Price, G. J. Falcone, P. Gormley, R. Malik, et al., Analysis of shared heritability in common disorders of the brain, Science 360 (2018). 
[227] G. L. Willingham-Storr, Parental experiences of caring for a child with intellectual disabilities: A uk perspective, Journal of Intellectual Disabilities 18 (2014) 146-158.

[228] J. G. Zwicker, S. W. Yoon, M. MacKay, J. Petrie-Thomas, M. Rogers, A. R. Synnes, Perinatal and neonatal predictors of developmental coordination disorder in very low birthweight children, Archives of disease in childhood 98 (2013) 118-122.

[229] C. A. Press, K. G. Knupp, K. E. Chapman, Parental reporting of response to oral cannabis extracts for treatment of refractory epilepsy, Epilepsy \& Behavior 45 (2015) 49-52.

[230] O. Zerbo, S. Modaressi, K. Goddard, E. Lewis, B. H. Fireman, M. F. Daley, S. A. Irving, L. A. Jackson, J. G. Donahue, L. Qian, et al., Vaccination patterns in children after autism spectrum disorder diagnosis and in their younger siblings, JAMA pediatrics 172 (2018) 469-475.

[231] S. Milberger, J. Biederman, S. V. Faraone, L. Chen, J. Jones, Is maternal smoking during pregnancy a risk factor for attention deficit hyperactivity disorder in children?, The American journal of psychiatry (1996).

[232] M. Aronson, B. Hagberg, C. Gillberg, Attention deficits and autistic spectrum problems in children exposed to alcohol during gestation: a follow-up study, Developmental Medicine \& Child Neurology 39 (1997) $583-587$.

[233] K. Sarimski, Behavioural phenotypes and family stress in three mental retardation syndromes, European Child \& Adolescent Psychiatry 6 (1997) 26-31.

[234] B. M. Hicks, S. C. South, A. C. DiRago, W. G. Iacono, M. McGue, Environmental adversity and increasing genetic risk for externalizing disorders, Archives of general psychiatry 66 (2009) 640-648.

[235] J.-Y. An, A. S. Cristino, Q. Zhao, J. Edson, S. M. Williams, D. Ravine, J. Wray, V. M. Marshall, A. Hunt, A. J. O. Whitehouse, et al., Towards a molecular characterization of autism spectrum disorders: an exome sequencing and systems approach, Translational psychiatry 4 (2014) e394-e394. 
[236] S. Dong, M. F. Walker, N. J. Carriero, M. DiCola, A. J. Willsey, Y. Y. Adam, Z. Waqar, L. E. Gonzalez, J. D. Overton, S. Frahm, et al., De novo insertions and deletions of predominantly paternal origin are associated with autism spectrum disorder, Cell reports 9 (2014) 16-23.

[237] A. Rzhetsky, S. C. Bagley, K. Wang, C. S. Lyttle, E. H. Cook Jr, R. B. Altman, R. D. Gibbons, Environmental and state-level regulatory factors affect the incidence of autism and intellectual disability, PLoS Comput Biol 10 (2014) e1003518.

[238] A. M. Grabrucker, Environmental factors in autism, Frontiers in psychiatry 3 (2013) 118.

[239] S. Herring, K. Gray, J. Taffe, B. Tonge, D. Sweeney, S. Einfeld, Behaviour and emotional problems in toddlers with pervasive developmental disorders and developmental delay: associations with parental mental health and family functioning, Journal of intellectual disability research 50 (2006) 874-882.

[240] G. H. Singer, Meta-analysis of comparative studies of depression in mothers of children with and without developmental disabilities, American journal on mental retardation 111 (2006) 155-169.

[241] L. Lecavalier, S. Leone, J. Wiltz, The impact of behaviour problems on caregiver stress in young people with autism spectrum disorders, Journal of intellectual disability research 50 (2006) 172-183.

[242] N. O. Davis, A. S. Carter, Parenting stress in mothers and fathers of toddlers with autism spectrum disorders: Associations with child characteristics, Journal of autism and developmental disorders 38 (2008) 1278 .

[243] L. E. Smith, M. M. Seltzer, H. Tager-Flusberg, J. S. Greenberg, A. S. Carter, A comparative analysis of well-being and coping among mothers of toddlers and mothers of adolescents with asd, Journal of autism and developmental disorders 38 (2008) 876.

[244] L. A. Dardas, M. M. Ahmad, Psychosocial correlates of parenting a child with autistic disorder, Journal of Nursing research 22 (2014) 183-191. 
[245] D. S. Mandell, L. D. Wiggins, L. A. Carpenter, J. Daniels, C. DiGuiseppi, M. S. Durkin, E. Giarelli, M. J. Morrier, J. S. Nicholas, J. A. Pinto-Martin, et al., Racial/ethnic disparities in the identification of children with autism spectrum disorders, American journal of public health 99 (2009) 493-498.

[246] C. L. Neece, S. A. Green, B. L. Baker, Parenting stress and child behavior problems: A transactional relationship across time, American journal on intellectual and developmental disabilities 117 (2012) 48-66.

[247] K. Povee, L. Roberts, J. Bourke, H. Leonard, Family functioning in families with a child with down syndrome: a mixed methods approach, Journal of Intellectual Disability Research 56 (2012) 961-973.

[248] N. Rodas, S. Zeedyk, B. Baker, Unsupportive parenting and internalising behaviour problems in children with or without intellectual disability, Journal of Intellectual Disability Research 60 (2016) 12001211.

[249] K. B. Kyzar, A. P. Turnbull, J. A. Summers, V. A. Gómez, The relationship of family support to family outcomes: A synthesis of key findings from research on severe disability, Research and Practice for Persons with Severe Disabilities 37 (2012) 31-44.

[250] G. T. Fujiura, The political arithmetic of disability and the american family: A demographic perspective, Family Relations 63 (2014) 7-19.

[251] Y.-P. Huang, M.-y. Chang, Y.-L. Chi, F.-C. Lai, Health-related quality of life in fathers of children with or without developmental disability: the mediating effect of parental stress, Quality of life research 23 (2014) $175-183$.

[252] S. Magaña, H. Li, E. Miranda, R. Paradiso de Sayu, Improving health behaviours of 1 atina mothers of youths and adults with intellectual and developmental disabilities, Journal of Intellectual Disability Research 59 (2015) 397-410.

[253] N. V. Ekas, L. Timmons, M. Pruitt, C. Ghilain, M. Alessandri, The power of positivity: Predictors of relationship satisfaction for parents of children with autism spectrum disorder, Journal of autism and developmental disorders 45 (2015) 1997-2007. 
[254] D. McConnell, A. Savage, Stress and resilience among families caring for children with intellectual disability: Expanding the research agenda, Current developmental disorders reports 2 (2015) 100-109.

[255] L. Marsh, P.-L. Warren, E. Savage, "something was wrong": A narrative inquiry of becoming a father of a child with an intellectual disability in ireland, British Journal of Learning Disabilities 46 (2018) 216-224.

[256] D. J. Laxman, B. A. McBride, L. M. Jeans, W. J. Dyer, R. M. Santos, J. L. Kern, N. Sugimura, S. L. Curtiss, J. M. Weglarz-Ward, Father involvement and maternal depressive symptoms in families of children with disabilities or delays, Maternal and Child Health Journal 19 (2015) 1078-1086.

[257] S. R. Cohen, S. Zeedyk, L. A. Tipton, N. V. Rodas, J. Blacher, Fathers of children with or without id: Understanding long-term psychological symptoms, Journal of Intellectual Disability Research 60 (2016) 295307.

[258] L. Marsh, M. Brown, E. McCann, The views and experiences of fathers of children with intellectual disabilities: A systematic review of the international evidence, Journal of Policy and Practice in Intellectual Disabilities 17 (2020) 79-90.

[259] X. Hu, Chinese fathers of children with intellectual disabilities: their perceptions of the child, family functioning, and their own needs for emotional support, International Journal of Developmental Disabilities (2020) 1-9. 